\title{
INFLUÊNCIA VARIETAL E DO SOLO NO ESTADO NUTRICIONAL NA CANA-DE-AÇÚCAR (Saccharum spp) PELA ANÁLISE FOLIAR*
}

\author{
Henrique PaUlo HaAg*** \\ JosÉ ORLANDO FILHO**
}

\section{RESUMO}

Com o objetivo de se estudar o comportamento varietal e do solo na concentração de macronutrientes nas folhas de cana-de-açúcar e, ao mesmo tempo, executar o levantamento do estado nutricional das variedades através da análise foliar, instalaram-se ensaios em quatro Grandes Grupos de Solos cultivando 16 plantadas sob idênticas condições de clima, adubação, tratos culturais, idade, estado de sanidade e procedência de mudas.

O delineamento estatístico foi o de blocos ao acaso com 16 tratamentos (variedades) e 4 repetições. Realizou-se a amostragem foliar aos 4 meses de idade, tomando-se os $20 \mathrm{~cm}$ centrais da folha +3 (20 por parcela), desprezando-se a nervura principal. Determinaram-se os macronutrientes (nitrogênio, fósforo, potássio, cálcio, magnésio e enxofre) os quais foram expressos em percentagem de matéria seca.

Os ensaios foram colhidos aos 18 meses de idade, sendo que para cada um deles determinou-se as produtividades em toneladas por pol/ha.

\section{INTRODUÇÃO}

A produção de uma cultura pode ser elevada pela ação de dois fatores: primeiro, pelo aumento da área de cultivo que vem a ser a extensão da fronteira agrícola e segundo, pela elevação da produtividade.

Dentre os fatores que contribuem para o aumento da produção por unidade de área, podemos citar: variedade, clima, práticas culturais e características físicas e químicas do solo. A adubação correta e adequada

* Parte da dissertação apresentada à ESALQ-USP, pelo primeiro autor, para obtenção do grau de Mestre em Solos e Nutrição de Plantas. Entregue para publicaçăo em 28/5/1976.

* Eng. ${ }^{*}$ Agr. ${ }^{\circ}$, Chefe da Divisão Agronômica da Coordenadoria Regional Sul do Planalsucar. Araras, SP.

*** Professor Adjunto do Departamento de Química, ESALQ, USP. 
influi decisivamente nas propriedades químicas do solo, a qual é, entre as variáveis interferentes na produtividade, uma das possíveis de sofrerem modificações. WILLIAMS \& COUSTON (1962), observaram que, para aumentos de $100 \%$ na produção por unidade de área, a adubação pode contribuir com $40 \%$ dessa elevação.

Conforme mostraram HUMBERT (1974), CRUZ (1973), VAN DILLEWIJN (1952) e MARTIN, citado por VAN DILLEWIJN (1952), nem sempre diferentes variedades de cana-de-açúcar reagem de modo similar a uma mesma adubação.

Atualmente, devido à alta participação da adubação no custo de produção da cana-de-açúcar, existe um grande interesse dos produtores em se fazer um controle de tal prática. Entre os vários métodos utilizados para a determinação das necessidades de fertilizantes para a cultura, destaca-se a diagnose foliar, que se baseia na relação entre o teor do elemento na folha e a produção. Esse valor, quando comparado a um padrão previamente estabelecido, pode indicar, segundo alguns autores, a quantidade de fertilizantes necessária para se alcançar determinada produção. Além disso, a diagnose foliar é também utilizada para se determinar o estado nutricional da planta.

A área cultivada com cana-de-açúcar tem alta representatividade no Estado de São Paulo, sendo que RUGAI \& ORLANDO F.' (1973), mostraram participação dos Grandes Grupos de Solos na referida cultura, onde o Latossol Roxo (LR) aparece com 44,20\%, o Latossol Vermelho Escuro-orto (LE) com 10,46\%, o Podzólico Vermelho Amarelo Variação-Laras com 9,43\% e a Terra Roxa Estruturada (TE) com $3,76 \%$. No Estado do Paraná estima-se que a Terra Roxa Estruturada (TE) tenha a maior representação na área canavieira.

No presente trabalho, estudou-se 16 variedades de cana-de-açúcar em 4 Grandes Grupos de Solos (LR, LE e PV1s no Estado de São Paulo e TE no Estado do Paraná), com o objetivo de:

a) - Verificar, para cada Grande Grupo de Solo, a influência varietal na concentração de macronutrientes das folhas.

b) - Observar o comportamento dos teores foliares de macronutrientes das variedades, em função do Grande Grupo de Solo.

c) - Executar o levantamento do estado nutricional das variedades em relação ao nitrogênio, fósforo, potássio, cálcio, magnésio e enxofre pela análise foliar. 


\section{REVISÃO DA LITERATURA}

Tendo em vista os objetos do presente trabalho, a revisão de literatura foi abordada sob três aspectos: influência varietal na diagniose foliar; influência do solo na diagnose foliar e padrões da diagnose foliar.

\section{1 - Influência varietal na diagnose foliar}

Na Austrália, KING et alii (1953), estudaram a variação das percentagens de nitrogênio, com base na matéria seca em 6 variedades de cana-de-açúcar, encontrando valores que variavam de 1,29\% a 1,45\%.

SAMUELS et alii (1955), em Porto Rico, apresentaram os resultados obtidos em 8 anos de experimentação, com ensaios de adubação NPK, fatorial incompleto, onde realizaram a diagnose foliar. Agruparam os resultados em função das 13 variedades e dos 10 grupos de solos estudados. Os autores concluiram que, embora haja diferenças na composição foliar para os nutrientes estudados, entre as variedades no mesmo tipo de solo ou entre a mesma variedade, quando cultivado em condições de solo e clima diferentes, do ponto de vista prático, os valores foliares* padrões de $\mathrm{N}=1,68 \%, \mathrm{P}=0,18 \%$ e $\mathrm{K}=1,71 \%$, podiam ser utilizados para todas as variedades.

Ainda em Porto Rico, SAMUELS (1959) observou que a idade da cana-de-açúcar exerce influência na concentração de nutrientes na folha. Assim, o teor foliar de nitrogênio diminui com o avançar da idade da cana, sendo que este decréscimo é mais pronunciado na planta não irrigada e na soca do que na cana-planta. Não houve diferença significativa entre os teores de nitrogênio, para as variedades B. 41227, M. 336 e P.R. 980.

HALAIS (1959), em Mauritius, indicou os níveis adequados de nitrogênio, fósforo e potássio, baseados na $3 .^{a}$ folha para as variedades B. 37172 e Ebène 1/37, como sendo:

\begin{tabular}{lccc}
\hline & \multicolumn{3}{c}{ Níveis adequados para a diagnose foliar } \\
\cline { 2 - 4 } Variedades & $\mathrm{N} \%$ & $\mathrm{P} \%$ & $\mathrm{~K} \%$ \\
B. 37172 & 1,94 & $0,18-0,23$ & $1,08-1,33$ \\
Ebène $1 / 37$ & 1,74 & $0,17-0,22$ & $1,12-1,38$ \\
\hline
\end{tabular}

* $\mathrm{Na}$ presente revisão os resultados das análises químicas serão sempre expressos em percentagens de matéria seca. 
SAMUELS et alii (1960), em Porto Rico, estudou a influência do estágio de desenvolvimento da cana (número de folhas e idade) sobre o conteúdo de nutrientes nas folhas das variedades B. 41227 e M. 336, mostraram as diferenças que as mesmas apresentaram em relação à concentração foliar de nitrogênio, fósforo e potássio, quando sob idênticos tratamentos ( $\mathrm{n} .^{\circ}$ de folhas e idade); os maiores parametros encontrados entre as duas variedades foram: $\mathrm{N} \%=2,15-2,35 ; \mathrm{P} \%=0,18-$ 0,23 e $\mathrm{K} \%=1,34-1,80$.

HALAIS (1964), em Mauritius, apresentou dados a respeito de correções nos teores críticos de nitrogênio, fósforo e potássio, da 3.a folha, com relação a 6 variedades de cana-de-açúcar, quando comparados aos valores padrões: $\mathrm{N}=1,74 \%, \mathrm{P}=0,199 \%$ e $\mathrm{K}=1,38 \%$. Tais correções, que deverão ser adicionadas ou subtraídas dos valores padrões, variam de: $\mathrm{N} \%=-0,07 \mathrm{a}+0,06, \mathrm{P} \%=-0,014 \mathrm{a}+0,016$ $\mathrm{e} \mathrm{K} \%=-0,12 \mathrm{a}+0,10$.

Na Austrália, FAQUHAR (1951), mostrou que existem diferenças consideráveis nos índices ótimos, das variedades cultivadas em "North Queensland". Como exemplo, citou as variedades Q 57 e Pindar, onde o índice ótimo da primeira em relação à segunda foi de $95 \%$, em relação ao nitrogênio, $110 \%$ em relação ao fósforo e $105 \%$ em relação ao potássio.

EVANS (1965), na Guiana Inglesa, ressaltou que não tem encontrado diferenças marcantes nos teores de nutrientes nas folhas /de variedades comerciais, embora admite-se que essa possibilidade pudesse ocorrer. O mesmo autor indicou que CLEMENTS, no Havaí, não menciona os efeitos varietais como sendo de maior importância nos trabalhos de "crop-log".

No Brasil, GALLO et alii (1968), efetuaram um levantamento do estado nutricional de canaviais do Estado de São Paulo, pela análise foliar, para macro e micronutrientes, utilizando as variedades CB 41-76 e Co 419, cultivadas em diversos Grandes Grupos de Solos. As amostras constituiam-se de folhas +3 , coletadas de 89 campos, distribuídos em 32 locais, aos 4 e 9 meses de idade, para a cana-planta. A porção analisada foi os 20 centímetros centrais, desprezando-se a nervura principal.

Foram anotadas diferenças significativas na concentração dos nutrientes nas folhas. Essas diferenças podem ser atribuídas aos seguintes fatores: variedade, idade da cana na amostragem e tipo de cultura. Os teores de nitrogênio, fósforo e magnésio foram significativamente mais elevados na variedade Co 419.

Pelo exame dos dados a seguir, observam-se as oscilações apresentadas pelas variedades: 
Elementos

Variedades

Co 419

CB $41-76$

$\begin{array}{lll}1,86 & 1,77 & \mathrm{~N} \% \\ 0,16 & 0,15 & \mathrm{P} \% \\ 1,26 & 1,46 & \mathrm{~K} \% \\ 0,50 & 0,56 & \mathrm{Ca} \% \\ 0,27 & 0,17 & \mathrm{Mg} \%\end{array}$

Em Mauritius, HALAIS \& NABABSING (1971), fixaram os índices foliares adequados, em relação ao nitrogênio, para as variedades estudadas, como segue: M. $13 / 56=2,17 \% ;$ M. $93 / 48=2,13 \%$; M. $147 / 44$ $=2,04 \%$ e $\mathrm{M} \cdot 442 / 51=2,02 \%$.

Na India, KIRTIKAR \& BAJPAI (1971) cultivando 18 variedades de cana-de-açúcar, em blocos ao acaso com 3 repetições onde todas as parcelas receberam $134,4 \mathrm{~kg}$ de $\mathrm{N} / \mathrm{ha}$, e analisando as folhas na época da colheita, para nitrogênio, fósforo, potássio, cálcio e magnésio, verificaram que as variedades apresentaram os seguintes parâmetros de variação: $\mathrm{N} \%=0,312-0,770 ; \mathrm{P} \%=0,047-0,127 ; \mathrm{K} \%=0,0400-1,040$; $\mathrm{Ca} \%=0,210-0,530$ e $\mathrm{Mg} \%=0,090-0,260$.

GOSNELL \& LONG (1971), na Rodésia, utilizando os 20 centímetros centrais da $3 .^{a}$ folha, descartando a nervura principal, (cana-planta, amostragem aos 5 meses de idade), mostraram a influência varietal na composição de nitrogênio, fósforo, potássio, cálcio e magnésio nas folhas, encontramos os seguintes parâmetros de variação: $\mathrm{N} \%=1,54-1,92$; $\mathrm{P} \%=0,140-0,172 ; \mathrm{K} \%=1,43-1,80 ; \mathrm{Ca} \%=0,212-0,358$ e $\mathrm{Mg} \%=0,148-$ 0,212 .

Na Guiana, McLEAN (1973), desenvolvendo trabalhos em cana-soca, com a finalidade de verificar o comportamento das 4 variedades principais de cana-de-açúcar: B. 41227 , B. 51116, D. 37/46 e D.141/46, no que diz respeito às variações de níveis ótimos para a diagnose foliar, verificou que os níveis foliares de nitrogênio da D. 141/46 aprasentaram-se significativamente mais baixos que os correspondentes a variedade B. 41227; para a idade de 12-15 semanas; tais níveis foram de 1,60\% de $\mathrm{N}$ para a $\mathrm{D} .141 / 46$ e $2,00 \%$ de $\mathrm{N}$ para a $\mathrm{B} .41227$.

Diferenças significativas nos níveis foliares para o nitrogênio, não foram encontradas entre a B. 41227 e as outras duas variedades. 
No ano de 1974, na África do Sul, no XV Congresso Internacional de ISSCT*, durante o painel de discussão sobre diagnose foliar, diversos especialistas no assunto emitiram opiniões sobre a influência varietal na diagnose foliar.

Assim:

CHEONG (ISSCT-1974), observou que em Mauritius, logo que uma variedade é estabelecida, a mesma é colocada em ensaios fatoriais NK, nas regiões canavieiras mais representativas, para a determinação dos níveis adequados em relação à diagnose foliar. Obtem-se, deste modo, valores específicos para cada variedade, ao mesmo tempo que se fazem correções para os estágios de crescimento da planta, em função dos teores de nutrientes nas folhas.

HUMBERT (ISSCT-1974), representante dos EEUU no referido painel, mencionou que as variedades de cana-delaçúcar diferem grandemente no desenvolvimento do sistema radicular; e isto é refletido naturalmente nos tecidos da planta, acima do solo.

CLEMENTS (ISSCT-1974), do Havaí, acredita que realmente as variedades possam apresentar diferenças na composição foliar, mas isto seria devido às diferenciações nos teores de umidade nos tecidos das mesmas. E, se a umidade do tecido fosse usada como um fator de correção, estas diferenças seriam eliminadas.

Por último, MORBELY (ISSCT-1974), representando a África do Sul, esclareceu que, em seu país, devido a NCo 376 compreender acima de 50,\% na produção total de cana-de-açúcar, não tem havido, na prática, preocupações em fatores de correção varietal, para a diagnose foliar. Porém, observações realizadas em novas variedades têm mostrado que os níveis críticos para o nitrogênio e potássio diferem da NCo 376 . Os valores de fósforo parecem ser similares para todas as variedades observadas.

ALVAREZ (1974), na Venezuela, trabalhando com 5 variedades de cana-de-açúcar, em ensaios fatoriais NPK, $3 \times 3 \times 3$, cana-planta, realizando a amostragem foliar da $3 .^{\mathrm{a}}, 4 .^{\mathrm{a}}, 5 .^{\mathrm{a}}$ e $6 .^{\mathrm{a}}$ folhas aos 110 dias de idade e determinando a umidade, fósforo e potássio nas bainhas e o nitrogênio, nas lâminas, sem a nervura principal, encontrou diferenças significativas entre os teores de umidade, nitrogênio e fósforo das folhas, para diferentes variedades. $O$ autor indicou ainda a necessidade de se estabelecer níveis ótimos de fertilização para cada variedade.

BOWEN (1975), no avaí, observou que a composição mineral da cana-de-açúcar é fortemente afetada por fatores fisiológicos e ambien-

* International Society of Sugar Cane Tecnologists. 
tais, tais como temperatura do ar e do solo, umidade do solo, interações entre nutrientes do solo e suas absorções pelas raizes, diferenças varietais e idade da planta. O autor mencionou também que, embora muitos estudos tenham sido conduzidos no sentido de se observar os efeitos da temperatura e umidade sobre a acumulação de nutrientes nos tecidos da cana-de-açúcar, relativamente pouca pesquisa tem sido conduzida para se verificar a influência das interações de nutrientes, efeitos varietais e idade da planta, sobre os níveis nutricionais da mesma.

\section{2 - Influência do solo na diagnose foliar}

MALAVOLTA et alii (1963), no Brasil, desenvolvendo 34 ensaios fatoriais sem repetições, NPK, $3 \times 3 \times 3$, com a variedade CB 41-76, em zonas canavieiras do Estado de São Paulo, sobre os solos: Terra Roxa Misturada* (latossol Vermelho Amarelo fase arenosa-LVa e/ou Latossol Roxo-LR), Terra Roxa Legítima* (Terra Roxa Estruturada-TE e/ou Latossol Roxo-LR) e Solos de Tipos Diversos, verificaram existir poucas variações entre os níveis críticos da diagnose foliar, determinados para os 3 grupos de solos, ou sejam:

\begin{tabular}{lccc} 
Solos & \multicolumn{3}{c}{ Niveis Adequados } \\
\cline { 2 - 4 } & N\% & P\% & K\% \\
\hline $\begin{array}{l}\text { Solos de Tipos Diversos } \\
\quad \text { (INa e ou LR) }\end{array}$ & 1,93 & 0,172 & 1,58 \\
Terra Roxa Legítina & & & \\
$\quad$ (TE e ou LR) & 1,89 & 0,184 & 1,65 \\
Terra Roxa Misturada & 1,90 & 0,184 & 1,67
\end{tabular}

Em Trinidade, VITLOS \& LAWRIE (1963), desenvolveram ensaios fatoriais NPK, $3 \times 3 \times 3$, com a variedade B. 41227 , cana-soca, em 4 tipos de solos. Realizaram a diagnose foliar aos 4 meses de idade amostrando a folha +1 . Os autores verificaram a influência do solo na diagnose foliar, mostrando os níveis foliares adequados de nitrogênio, fósforo e potássio, em função de solo, que são:

* Correspondência na classificação moderna, segundo FRANÇA \& DEMATTE (1970): Terra Roxa Misturala = Latossol Vermelho Amarelo fase arenosa (LVa) e ou Latossol Ruxo (LR).

Terra Roxa Legítima $=$ Terra Roxa Estruturada (TEL Latossol Roxo (LR).

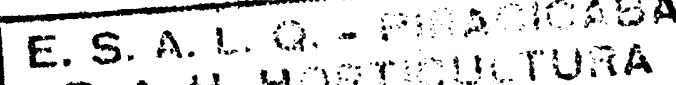

D. A. H. Hor

No

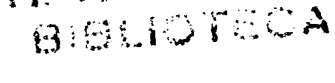


Tipos de solos

\begin{tabular}{lll}
\multicolumn{3}{c}{ Níveis adequados } \\
\hline $\mathrm{N} \%$ & $\mathrm{P} \%$ & $\mathrm{~K} \%$
\end{tabular}

Mac Bean Sand

GALLO et alii (1968), executaram o levantamento nutricional de 2 variedades de cana-de-açúcar (CB 41-76 e Co 419) em canaviais do Estado de São Paulo, com a amostragem das folhas aos 4 e 9 meses de idade, nos solos: Latossol Roxo, Podzolizados de Lins e Marília, Podzólico Vermelho Amarelo-orto, Podzólico Vermelho Amarelo-Laras, Latossol Vermelho Amarelo-orto e Latossol Vermelho Escuro. Os autores observaram que os Grandes Grupos de Solos não tiveram, em geral, influência consistente, exceto no teor de ferro, significativamente mais elevado nas folhas das canas cultivadas no Latossol Roxo, em relação aos demais. Outras diferenças nos teores de nitrogênio, cálcio, magnésio e cobre foram constatadas, sem predominância de um dos solos.

SAMUELS (1969), no livro "Diagnosis for Sugarcane" mencionou que são dispensáveis correções ou ajustamentos em programa de diagnose foliar para a cana-de-açúcgar em funpão do tipo, série ou outra classificação do solo. Isto porque a planta de cana-de-açúcar é capaz de integrar todas as variáveis presentes no solo e oferecer, através da diagnose foliar, uma resposta a respeito de suas necessidades nutricionais.

No Brasil, SILVA (1972), efetuou um levantamento do estado nutricional da cana-de-açúcar, variedade $\mathrm{CB}$ 41-76, em 10 séries de solos do município de Piracicaba, Estado de São Paulo, através da análise química de amostras da terceira e quarta folhas, com objetivo de verificar a necessidade de adubação.

Os resultados concernentes ao nível foliar de macronutrientes, nível crítico fisiológico e econômico* e necessidade de adubação foram os seguintes:

* MALAVOLTA et alii (1962) consideraram "Nível crítico fisiológico e econômico" como sendo a faixa de teores de um elemento na folha, abaixo da quel a produção é limitada e acima da qual o uso de adubos não é mais cconômico. 
a) - Para o nitrogênio, embora o nível foliar estivesse aquém do cr,tico, não foi observada resposta à adubação.

b) - Em função do tipo de solo, os níveis críticos encontrados para nitrogênio, fósforo e potássio foram:

Solos

Concentração dos nutrientes

$\mathrm{N} \% \mathrm{P} \% \mathrm{~K} \%$

Terra Roxa Legítima

$\begin{array}{llll}\text { (Terra Roxa Estruturada e ou Latossol Roxo) } & 1,94 & 0,186 & 1,67\end{array}$

Terra Roxa Misturada

(Latossol Vermelho Amarelo fa-se arenosa

e ou Latossol Roxo)

$1,95 \quad 0,172 \quad 1,61$

Diversos Tipos

1,93

$0,185 \quad 1,68$

c) - Os dados encontrados nas folhas variam de $1,25 \%$ a $1,84 \%$ : para nitrogênio, de $0,14 \%$ a $0,21 \%$ para fósforo, de $0,56 \%$ ! a $1,60 \%$ para potássio, de $0,60 \%$ a $0,90 \%$ para cálcio, de $0,18 \%$ a $0,25 \%$ para magnésio e de $0,16 \%$ a $0,25 \%$ para enxofre.

\section{3 - Padrões da diagnose foliar}

LANDRAU \&SAMUELS (1954), em Porto Rico, estudaram a adubação nas variedades P.R. 902, P.R. 905, P.O.J. 2872 e M. 28 e verificaram que seus rendimentos relativos mantiveram aumentos similares aos distintos níveis. A diagnose foliar, aplicada na terceira rebrota, mostrou que valores menores que $1,39 \%$ de nitrogênio nas folhas representavom uma insuficiência desse elemento e sua aplicação significava um aumento nos rendimentos. Valores de $0,16 \%$ de fósforo, indicaram uma deficiência do elemento, enquanto que teores de $0,20 \%$ ou mais, não responderam à adição de adubos fosfatados. Os valores de potássio, iguais ou maiores que 2,00\%, não acusaram aumentos significativos nos rendimentos, em função da adubação potássica.

CURY et alii (1957), no Brasil, realizaram o primeiro trbalho de diagnose foliar em cana-de-açúcar. Utilizaram avariedade Co 419, em ensaio fatorial PK, 4x4, cana-planta, sendo que diagnose foliar foi aplicada aos 8, 11 e 15 meses de idade, tomando-se pa ra análises quí- 
micas a porção mediana da $3 .^{a}$ e $4 .^{a}$ folhas, sem a nervura principal. As análises revelaram uma variação significante nos teores de fósforo e potássio nas folhas, em função desses elementos fornecidos na adubação. Notaram também, um efeito significativo da época da amostragem, nos teores de fósforo e potássio nas folhas. Os dados obtidos, sugeriram os níveis faliares de aproximadamente $0,35 \%$ para o fósforo (plantas com 8 meses de idade) e acima de 1,5\% de potássio (plantas com 15 meses de idade).

Em Porto Rico, SAMUELS et alii (1951) apresentaram os níveis níveis foliares de nitrogenio, fósfori e potássio, considerados como adequados para Porto Rico e Havaí e expressos em percentagem de matéria seca da lâmina foliar, como sendo: Havaí $(\mathrm{N} \%=2,0 ; \mathrm{P} \%=0,21 \mathrm{e}$ $\mathrm{K} \%=1,75)$ e porto Rico $(\mathrm{N} \%=1,8 ; \mathrm{P} \%=0,23$ e $\mathrm{K} \%=1,56)$.

MALAVOLTA et alii (1959a), no Brasil, estudando os efeitos residuais de fósforo e potássio em cana-soca, variedade Co 419 , e coletando folhas aos 6, 8 e 10 meses de idade, concluiram que amelhor época para a diagnose foliar foi aos 6 meses de idade. Os autores admitiram como suficiente o nível de $0,15 \%$ de fósforo, baseado na porção mediana das 3. e 4. ${ }^{a}$ folhas, sem a nervura principal, para se obter boas colheitas. As concentrações foliares para o potássio, foram de difícil interpretação, devido à interação significante entre fósforo e potássio.

Ainda no Brasil, MALAVOLTA et alii (1959b), utilizando a variedade Co 419, cana-planta, em solo arenoso da região canavieira do Estado de São Paulo, e valendo-se de ensaio fatorial NPK, 3x3x3, estudaram a diagnose foliar, com amostragens aos 4, 6, 8, 10, 12 e 15 meses de idade, tomando a $3 .^{a}$ e $4 .^{a}$ folhas, sem a nervura principal. Como não foram obtidas respostas do nitrogênio e fósforo, os autores consideraram os níveis foliares de $2,0 \%$ a $2,5 \%$ de nitrogenio e $0,20 \%$ de fósforo como adequados. Em relação ao potássio, houve variação nos teores foliares, isto em função da época de amostragem e das doses de potássio empregadas na adubação. Os resultados indicaram que a coleta das amostras aos 4 meses após o plantio, é a mais adequada e a concentração foliar de potássio deve situar-se entre $1,00 \%$ a $1,25 \%$. As análises foliares de cálcio e magnésio, realizadas aos 4 meses de idade, mostraram os seguintes parâmetros de variação: $\mathrm{Ca}=0,68 \%-11,21 \%$ e $\mathrm{Mg}=0,20 \%$. $-0,55 \%$.

INNES (1959), na Jamaica, determinou os níveis adequados para a diagnose foliar em cana-soca, amostragem aos, 5 meses de idade, com base na porção mediana da $3 .^{a}$ folha, sem a nervura principal, como sendo: $\mathrm{N} \%=1,93 ; \mathrm{P} \%=0,20$ e $\mathrm{K} \%=1,28$.

DU TOIT (1959), na África do Sul, mencionou que na utilização da diagnose foliar (porção mediana da $3 .^{a}$ folha, amostrada entre 5-12 meses de idade), não se deve esperar resposta à adição de fertilizantes 
(fosfatados e potássicos), quando os valores foliares atingiram $\mathbf{0 , 2 2} \%$ de fósforo e $1,24 \%$ de potássio respectivamente.

Na Guiana Inglesa, EVANS (1961), estudou os níveis de quatro nutrientes (nitrogenio, fósforo, potássio e cálcio) nas folhas de cana-de-açúcar, com amostragem aos 4 meses de idade, da folha +1 . Para o nitrogenio o teor ótimo foi de $1,9 \%$, com precipitações pluviométricas de seis a dez polegadas*, bem distribuídas num período de quatro semanas antes da amostragem. Precipitações acima de onze polegadas induziam um decréscimo no teor de nitrogênio nas folhas, principalmente devido à lixiviação e à redução da atividade biológica no solo pela deficiência de oxigênio. O valor ótimo para o fósforo, situa-se entre $0,20 \%$ e $0,21 \%$; e uma queda, nesse teor, para $0,17 \%$ ou $0,18 \%$, no final do período do crescimento ativo, não tinha grande efeito na produção. O nível ótimo de potássio na folha foi de 1,25\%; e certas regiões da Guiana, que apresentavam solos com altos teores de magnésio, induziam a deficiência de potássio. Tal situação era diagnosticada pela análise da folha que apresentava $0,60 \%$ de magnésio e 0,70\% de potássio. Em condições normais, o teor de magnésio variava de $0,15 \%$ a $0,30 \%$. O nível crítico de cálcio estava em torno de $0,13 \%$ e os sintomas de deficiência eram percebidos quando esses níveis situavam-se abaixo de $0,09 \%$ de cálcio nas folhas.

HALAIS (1962), Mauritius, estabeleceu os níveis ótimos para a diagnose foliar para cana-soca, idade de 5 meses, baseado na porção mediana da $3{ }^{\text {a }}$ folha, sem a nervura principal, como sendo: $\mathrm{N} \%=1,95$; $\mathrm{P} \%=0,21$ e $\mathrm{K} \%=1,25$.

GALLO et alii (1962), no Brasil, realizaram um trabalho com o objetivo de determinar, a partir de dados da experimentação local, um sistema adequado de amostragem de folhas de cana-de-açúcar, para análise foliar. Efetuaram amostragem de folhas de cana-planta de um experimento fatorial NPK, $2 \times 2 \times 2$, obedecendo ao seguinte critério: folha $+1,+2,+3$ e +4 ; e a seguinte separação para análise: porção mediana da lâmina sem a nervura principal, porção mediana da lâmina com a nervura principal e bainha. As folhas foram coletadas em seis épocas, ou sejam 4, 5, 6, 7, 8 e 9 meses de idade. Dos resultados obtidos, os autores indicaram selecionar a folha da posição +3 , em plantas de 4 e 8-9 meses de idade e tomar os 20 centímetros centrais da lâmina, com exclusão da nervura principal, para a determinação dos teores totais de nitrogênio, fósforo, potássio, cálcio e magnésio.

No Brasil, MALAVOLTA et alii (1963), utilizando-se de 34 ensaios

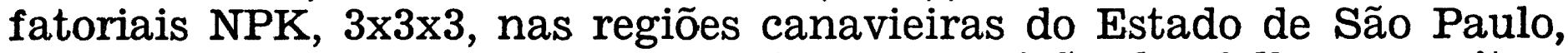
verificaram que, de um modo geral, a composição das folhas em nitro-

* 1 polegada $=2,54 \mathrm{~cm}$. 
gềnio, fósforo e potássio, refletiam muito bem as respostas da cana- planta à adubação. Utilizaram para análise foliar, a porção mediana da $3 .^{a}$ e $4 .^{a}$ folhas colhidas aos 4-5 meses de idade, sem a nervura principal. A variação dos níveis críticos econômicos para os ensaios, em função do preço dos adubos, foi muito pequena $(1,84 \%$ a $1,95 \%$ para $o$ nitrogênio, $0,17 \%$ a $0,186 \%$ para o fósforo e $1,67 \%$ para o potássio) .

Ainda no Brasil, MALAVOLTA \& COURY (1963) apresentaram os teores foliares de macronutrientes, considerados normais e deficientes para a cana-de-açúcar, como sendo:

\begin{tabular}{lll}
\hline & \multicolumn{2}{c}{ Teores Foliares } \\
\cline { 2 - 3 } Elementos & Deficientes & Normais \\
\hline \hline $\mathrm{N} \%$ & $1,00-1,65$ & $1,66-2,50$ \\
$\mathrm{P} \%$ & $0,10-0,18$ & $0,18-0,25$ \\
$\mathrm{~K} \%$ & $0,62-1,00$ & $1,00-1,25$ \\
$\mathrm{Ca} \%$ & 0,06 & 0,34 \\
$\mathrm{Mg} \%$ & $0,02-0,05$ & 0,10 \\
$\mathrm{~S} \%$ & 0,13 & 0,17 \\
\hline
\end{tabular}

Os autores observaram ainda, que as variações encontradas foram devidas às diferenças de época de amostragem, tipo de folha analisada, variedade cultivada e grau de deficiência.

En Trinidad, VITLOS \& LAWRTE (1963), trabalhando com a variedade B. 41227 , em ensaios fatoriais NPK, $3 \times 3 \times 3$, cana-soca e em 5 tipos de solos, aplicaram a diagnose foliar. A amostragem foi realizada aos 3, 4, 5, 6 e 7 meses, utilizando-se a porção mediana da 3. ${ }^{a}$ folha, sem a nervura principal. Os autores concluiram que a melhor idade para a amostragem foi a de 4 meses e tendo em vista os solos estudados; apresentaram as variações dos níveis adequados para a diagnose foliar, como sendo: $\mathrm{N} \%=1,7-2,6 ; \mathrm{P} \%=0,20-0,29$ e $\mathrm{K} \%=1,1-1,9$.

POIDEVIN (1964), apresentou os teores foliares adequados de nitrogênio, fósforo e potássio, para cana-planta, na Guiana Inglesa. Os resultados tiveram por base a porção mediana da folha +1 , sem a nervura principal, e foram mostrados em função de 3 idades da planta: 


\begin{tabular}{llll} 
& \multicolumn{3}{c}{ Idade da cana em semanas } \\
\cline { 2 - 4 } & 12 & 18 & 24 \\
\hline & & & \\
$\mathrm{N} \%$ & 2,50 & 2,25 & 2,00 \\
$\mathrm{P} \%$ & 0,22 & 0,20 & $0,18-0,20$ \\
$\mathrm{~K} \%$ & $1,20(\mathrm{ou}+)$ & $1,20(\mathrm{ou}+)$ & $1,20 \mathrm{ou}+$ )
\end{tabular}

GOLDEN \& RICAUD, na Louisiana, EEUU, citados por HUMBERT (1974), mostraram as concentrações de nutrientes nas folhas da canade-açúcar e os relacionaram com o estado nutricional da cultura, considerando os valores muito baixo, baixo, médio, alto e muito alto:

Estado Nutricional da cana-de-açúcar
Concentração de nutrientes nas folhas

$\begin{array}{lll}\mathrm{N} \% & \mathrm{P} \% & \mathrm{~K} \%\end{array}$

Muito Baixo

Baixo

Médio

Alto

Muito alto

$$
\begin{array}{r}
<\quad 1,25 \\
1,25-1,50 \\
1,50-1,75 \\
1,75-2,00 \\
>\quad 2,00
\end{array}
$$

$$
\begin{gathered}
<\quad 1,00 \\
1,00-1,25 \\
1,25-1,75 \\
1,75-2,00 \\
>\quad 2,00
\end{gathered}
$$

Na África do Sul, STEWARD (1969), indicou que não se deve esperar resposta à adubação potássica, quando o teor de potássio, com base na porção mediana do limbo da $3 .^{\mathrm{a}}$ folha, for de $1,10 \%$.

FOGLIATA \& DIP (1970), na Argentina, mostraram os resultados de 5 anos de experimentação de adubação com a variedade CP 48-103. Os autores aplicaram a diagnose foliar, utilizando para as análises químicas a porção mediana da folha +1 , sem nervura principal, amostrada aos 5 meses de idade, obtendo-se resposta apenas para o nitrogênio, onde o nível crítico foliar do mesmo variou de $1,76 \%$ a 1,82\%. Os teores foliares de fósforo oscilaram entre $0,15 \%$ a $0,18 \%$, enquanto que para o potássio o mesmo correspondeu a 1,15\%. AAs percentagens de cálcio e magnésio nas folhas acusaram bons conteúdos $(0,29 \%$ a $0,37 \%$ para o $\mathrm{Ca}$, e $0,14 \%$ a $0,19 \%$ para $\mathrm{Mg}$ ). 
No México, ESPINOZA (1973), indicou os teores adequados para a diagnose foliar, com base na porção mediana da $5 .^{a}$ folha, sem a nervura principal. Tais níveis, utilizados pelo Instituto de Melhoramento de Produção de Açúcar, são: $\mathrm{N} \%=1,5-2,0 ; \mathrm{P} \%=0,14-0,18 \mathrm{e}$ $\mathrm{K} \%=1,65-2,00$.

MALAVOLTA et alii (1974), no Brasil, no livro "Nutrição Mineral e Adubação de Plantas Cultivadas", apontaram concentrações foliares adequadas, para nitrogênio, fósforo, potássio e cálcio, referindo-se à porção mediana (nervura excluída) da $3 .^{a}$ e $4 .^{a}$ folhas, com idade de 4 a 6 meses, como sendo: $\mathrm{N} \%=2,0-2,5 ; \mathrm{P} \%=0,18-0,20 ; \mathrm{K} \%=1,00-1,25$ $\mathrm{e} \mathrm{Ca} \%=0,75-1,00$.

HUMBERT (1974), no livro "El Cultivo de la Caña de Azucar", mencionou que as variedades podem diferir muito em sua composição química. Assim, as quantidades de nutrientes absorvidas de um solo, por diferentes variedades, podem variar até $100 \%$. Assinalou, ainda, que os valores foliares de enxofre oscilam de 300 a 10.000 ppm, enquanto que teores foliares de $0,08 \%$ a $0,35 \%$ de magnésio, estão associados ao bom desenvolvimento da cana. O mesmo autor citou que FEILLAFE, em 1954, em Mauritius, não obteve aumentos de rendimentos na canade-açúcar, quando os níveis de magnésio nas folhas eram de $0,10 \%$ $0,20 \%$.

\section{4 - MATERIAL E MÉTODOS}

Solos

Utilizou-se de quatro Grandes Grupos de Solos:

- Latossol Roxo (LR) - na Usina Santa Elisa S/A, município de Sertãozinho, Estado de São Paulo.

- Latossol Vermelho Escuro-orto (LE) - na Estação Central Sul do Planalsucar, município de Araras, Estado de São Paulo.

- Podzólico Vermelho-variação Laras (PVls) Usina Bom Jesús S/A, município de Rio das Pedras, Estado de São Paulo.

- Terra Roxa Estruturada (TE) - na Usina Bandeirantes S/A município de Bandeirantes, Estado do Paraná.

As localizações aproximadas dos mesmos, em função da latitude, longitude e altitude, foram: 


Solo Latitude Longitude Oeste Altitude, metros)

\begin{tabular}{|c|c|c|c|}
\hline LR & $21 .^{\circ} 08^{\prime}$ & $48 .^{\circ} 01^{\prime}$ & 500 \\
\hline LE & $22 .^{\circ} 18^{\prime}$ & $47.0^{\circ} 23^{\prime}$ & 617 \\
\hline PVls & $22 .^{\circ} 49^{\prime}$ & 47.37 & 500 \\
\hline $\mathrm{TE}$ & $23 .^{\circ} 10^{\prime}$ & $47.0^{\circ} 23^{\prime}$ & 400 \\
\hline
\end{tabular}

A identificação do LE e TE, baseou-se em trabalho da SEITEC (1973), a do LR em FRANÇA \& DEMATTE (1971) e PVls, no Boletim n. 12 da Comissão de Solos (1960) .

Os solos foram amostrados e submetidos a análises químicas ( $\mathrm{pH}$, carbono, fósforo, potássio, cálcio e magnésio), seguindo metodologia descrita em CATANI e JACINTO (1974). A tabela 1 apresenta as características químicas dos solos e interpretação.

\section{Variedades *}

As 16 variedades de cana-de-açúcar (Saccharum spp), procedentes da Estação Central Sul do Planalsucar, em Araras, SP e provenientes de talhões sob controle de raquitismo, foram: CB 41-76; CB 45-155; CB 47-355; CB 49-260; CB 53-98; CB 56-156; CB 56-171; CB 61-80; IAC 50/134; IAC 51/205; IAC 52/150; IAC 52/326; Co 740; Co 775 NA 56-62; CP 51-22.

A representatividade das citadas variedades nas diferentes regiões canavieiras do Estado de São Paulo, é mostrada por AZZI (1971).

\section{Instalação dos Ensaios}

Os solos, após o devido preparo, foram sulcados na profundidade de $25 \mathrm{~cm}$. e no espaçamento de $1,50 \mathrm{~cm}$. As parcelas eram compostas de 6 sulcos de $10 \mathrm{~m}$ de comprimento, sendo que os sulcos das laterais funcionavam como bordaduras. A área total de cada parcela era de $90 \mathrm{~m}^{2}$. Separando as parcelas, no sentido transversal dos sulcos, fz-se "caminhamentos" de $1,00 \mathrm{~m}$ de largura.

As mudas, todas com a mesma idade (12 meses) e procedência, eram preparadas em toletes de 3 gemas, os quais foram selecionados $\mathrm{e}$

* As variedades foram mencionadas, segundo o sistema apresentado por DANIELS (1971). 


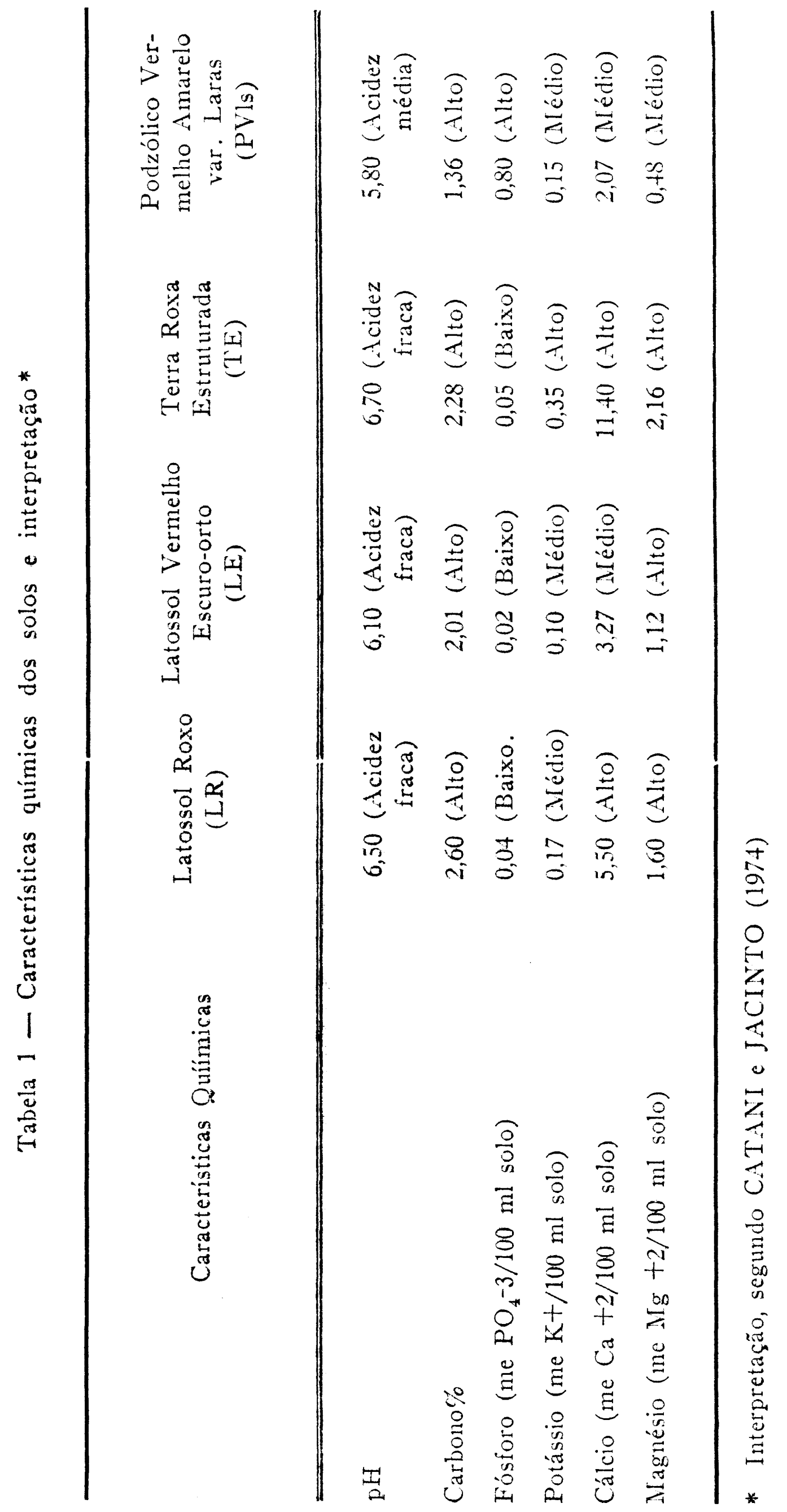


mergulados em solução de Aldrex * a $0,3 \%$ e Benlate ** a $0,06 \%$. Os podrões utilizados nas operações de corte eram desinfetados, previamente, em solução de Lysoform *** a $5 \%$.

As adubações utilizadas foram baseadas em ESPIRONELO \& OLIVEIRA (1972), assim como nas doses utilizadas rotineiramente em cada local. A tabela 2 mostra as formas, doses e épocas de aplicação dos fertilizantes, nos quatros solos.

O plantio constou de 30 toletes de 3 gemas por $10 \mathrm{~m}$ de sulco, os quais foram cobertos com uma camada aproximadamente de $5 \mathrm{~cm}$ de solo. O ciclo da cultura foi de 18 meses, (março de 1972 a setembro de

Tabela 2 - Doses e épocas de aplicação dos fertilizantes.

\begin{tabular}{|c|c|c|c|c|}
\hline & Plantio & 25 & 100 & 120 \\
\hline LR & $\begin{array}{l}\text { Cobertura } \\
(6 \text { meses) }\end{array}$ & 50 & - & - \\
\hline LE & $\begin{array}{l}\text { Plantio } \\
\text { Cobertura } \\
\text { (6 meses) }\end{array}$ & $\begin{array}{l}25 \\
50\end{array}$ & $\begin{array}{c}120 \\
-\end{array}$ & $\begin{array}{r}120 \\
-\end{array}$ \\
\hline $\mathrm{TE}$ & $\begin{array}{l}\text { Plantio } \\
\text { Cobertura } \\
\text { (6 meses) }\end{array}$ & $\begin{array}{l}40 \\
50\end{array}$ & $\begin{array}{l}150 \\
-\end{array}$ & $\begin{array}{c}100 \\
-\end{array}$ \\
\hline \multirow[t]{2}{*}{ PVls** } & $\begin{array}{l}\text { Plantio } \\
\text { Cobertura } \\
\text { (6 meses) }\end{array}$ & $\begin{array}{l}10 \\
40\end{array}$ & $\begin{array}{l}80 \\
-\end{array}$ & $\begin{array}{l}120 \\
-\end{array}$ \\
\hline & $\begin{array}{l}\text { Cobertura } \\
\text { (9 meses) }\end{array}$ & 40 & - & - \\
\hline
\end{tabular}

* N, P205 e K20, aplicados nas formas de suliato de amônio $(20 \% \mathrm{~N})$, superfosfato simples (20\% P205) e cloreto de potássio $(60 \% \mathrm{~K} 20)$.

* Para o PVls, além das quantidades de fertilizantes que constam na tabcla 2 foram aplicados, no plantio, $400 \mathrm{~kg}$ de torta de mamona por hectare.

* Aldrex - Shell do Brasil Ltda. - Rio de Janeiro - RJ.

** Benlate - Du Pont do Brasil - Industrias Químicas - S. Panlo.

*** Lysoform - Lysoform S/A - Indústrias Químicas - S. Patulo. 
1973). As precipitações pluviométricas, para os 4 solos, no referido período, são indicadas na tabela 3 .

Tanto as adubações como a cobertura dos sulcos e capinas, foram realizadas manualmente.

O delineamento estatístico escolhido foi o de blocos ao acaso, com 4 repetições (GOMES - 1963).

Efetuou-se a amostragem foliar aos 4 meses de idade, tomando-se os $20 \mathrm{~cm}$. centrais, sem a nervura principal, da folha +3 , de acôrdo com GALLO et alii (1962) .

Análises Químicas

Tabela 3 - Precipitação pluviométrica nos 4 solos, no período de março de 1872 a setembro de 1973.

\begin{tabular}{|c|c|c|c|c|}
\hline \multirow[b]{2}{*}{ Meses } & \multicolumn{4}{|c|}{ Precipitação em $\mathrm{mm}$} \\
\hline & $\begin{array}{c}\text { Latossol } \\
\text { Roxo } \\
\text { (LR) }\end{array}$ & $\begin{array}{l}\text { Latossol Ver- } \\
\text { melho Escuro- } \\
\text { orto (LE) }\end{array}$ & $\begin{array}{c}\text { Terra Roxa } \\
\text { Estruturada } \\
\text { (TE) }\end{array}$ & $\begin{array}{c}\text { Podzólico Ver- } \\
\text { melho Amarelo } \\
\text { var. Laras } \\
\text { (PVls) }\end{array}$ \\
\hline Março/1972 & 123 & 70 & 87 & 84 \\
\hline Abril & 91 & 19 & 197 & 53 \\
\hline Maio & 86 & 38 & 86 & 54 \\
\hline Junho & 0 & 4 & 2,5 & 5 \\
\hline Julho & 110 & 141 & 166 & 115 \\
\hline Agosto & 79 & 91 & 98 & 71 \\
\hline Setembro & 53 & 78 & 137 & 111 \\
\hline Outubro & 224 & 174 & 319 & 206 \\
\hline Novembro & 278 & 160 & 241 & 131 \\
\hline Dezembro & 255 & 1.34 & 122 & 125 \\
\hline Janeiro/1973 & 161 & 137 & 329 & 184 \\
\hline Fevereiro & 151 & 247 & 54 & 193 \\
\hline Março & 109 & 177 & 44 & 109 \\
\hline Abril & 156 & .71 & 29 & 54 \\
\hline Maio & 39 & 50 & 105 & 49 \\
\hline Junho & 8 & 29 & 100 & 36 \\
\hline Julho & 13,5 & 49 & 48 & 29 \\
\hline Agosto & 3 & 16 & 121 & 12 \\
\hline Setembro & 61 & 63 & 38 & 51 \\
\hline
\end{tabular}


As amostras foram preparadas e analisadas para nitrogênio fósforo, potássio, cálcio, magnésio e enxofre, seguindo-se técnicas convencionais utilizadas na área de Nutrição de Plantas do Departamento de Química da E.S.A. "Luiz de Queiróz", descritas em SARRUGE \& HAAG (1974) .

\section{Produção e Análises Tecnológicas}

Após o corte dos ensaios, as parcelas foram pesadas e logo em seguida, de cada uma delas, tomou-se, ao acaso 20 colmos, para as determinações de $\mathrm{pol}^{*}$ da cana, seguindo-se o método de BUCCHANAN (1966), onde utilizou-se a percentagem de fibra da cana, determinada pelo processo "australiano" descrito em MEADE (1967) .

\section{5 - RESULTADOS E DISCUSSÃO}

\section{1 - Nitrogênio}

As percentagens foliares de nitrogênio, para as 16 variedades nos 4 Grandes Grupos de Solos, com respectivas avaliações estatísticas (entre diferentes variedades no mesmo solo e para mesma variedade nos diferentes solos) se encontram na tabela 4, onde observa-se a influência varietal e do solo, nos teores foliares de nitrogênio.

Os parâmetros de variação encontrados para o nitrogênio, foram:

Solo Variações nos teores foliares de
nitrogênio

$\begin{array}{ll}\text { LR } & 2,28 \%-1,96 \% \\ \text { LE } & 2,57 \%-2,06 \% \\ \text { TE } & 2,59 \%-1,95 \% \\ \text { PV1s } & 2,29 \%-1,94 \%\end{array}$

* Pol, segundo PAYNE (1968), é o nome que se dá ao valor determinado numa única polarização do peso normal de $11 \mathrm{~m}$ produto do açúcar, perfazendo um volume total de $100 \mathrm{ml}$ e $20^{\circ} \mathrm{C}$, clarificado quando necessário, com sub-acetato de chumbo seco e fazendo a leitura num tubo de $200 \mathrm{~mm}$. de comprimento, utilizando-se a escala sacarimétrica de Bates - Jackson. Este têrmo é utilizado em cálculos como se fosse uma substância real. 
Dos nutrientes estudados, o nitrogênio foi o que apresentou os parâmetros mais baixos de variação. Os mesmos, para os 4 solos, são superiores àqueles encontrados por KING et alii (1953), na Austrália, SAMUELS et alii (1960), em Porto Rico, HALAIS (1959 e 1964) e HALAIS \& NABASING (1971) em Mauritius e GALLO et alii (1968) no Brasil. Porém, foram inferiores (erxeção ao parâmetro apresentado pelas variedades do solo LE) aos mostrados por McLEAN (1973) na Guiana, KIRTIKAR \& BAJPAI (1971) na India ,GOSNELL \& LONG (1971) na Rodésia e ALVAREZ (1974) na Venezuela, quando trabalharam com diferentes variedades de cana-de-açúcar.

De um modo geral, as variedades apresentaram classificações semeIhantes, quanto ao teor de nitrogênio nas folhas, nos 4 solos estudados (tabela 4).

É interessante citar que a CB 53-98 foi uma das variedades que apresentou nos 4 solos, os menores teores foliares de nitrogênio (tabela 4), porém, com produções em t de pol/ha bastante razoável (tabela 5), enquanto que a CB 56-171, apesar de seus altos valores nas percentagens de nitrogênio nas folhas, foi a variedade que acusou as menores produtividades de pol. Já a Co 740 mostrou elevados teores de nitrogênio e altas produçỗes de pol/ha.

As variedades CB 47-355, CB 53-98, CB 56-171, VB 61-80, IAC 51/205 e IAC 52/326, não indicaram diferenças significativas nos teores foliares de nitrogênio, quando cultivada nos 4 diferentes solos (tabela 4) mas, em relação à produtividade de pol, apresentaram significância (tabela 5).

No Latossol Vermelho Escuro-orto, todas as variedades revelaram as maiores percentagens de nitrogênio, em relação aos demais solos.

Realizou-se tambéb a análise conjunto para as 16 variedades, considerando-se os 4 Grandes Grupos de Solos (tabela 6) onde observa-se, ao compararmos a referida tabela com a tabela 1, que o teor de carbono do solo parece não ter influído nas percentagens foliares de nitrogênio, pois o PVls e TE, com respectivamente, $1,36 \%$ e 2,28\% de carbono no solo, apresentaram teores foliares de $2,11 \%$ de nitrogênio. Por outro lado, as diferenças entre os teores de nitrogênio nas folhas, considerando-se os 4 Grandes Grupos de Solos, foram inferiores àquelas encontrados por VITLOS \& LAWRIE (1963) em Trinidad e SILVA (1972) no Brasil.

Quanto ao levantamento do estado nutricional, quase a totalidade das variedades mostrou valores superiores a 2,00\% de nitrogênio nas folhas, considerado como adequado por MALAVOLTA et alii (1974) no Brasil. Tais resultados estariam de acordo e levemente superiores aos obtidos por INNES (1959) na Jamaica, EVANS (1961) na Guiana 


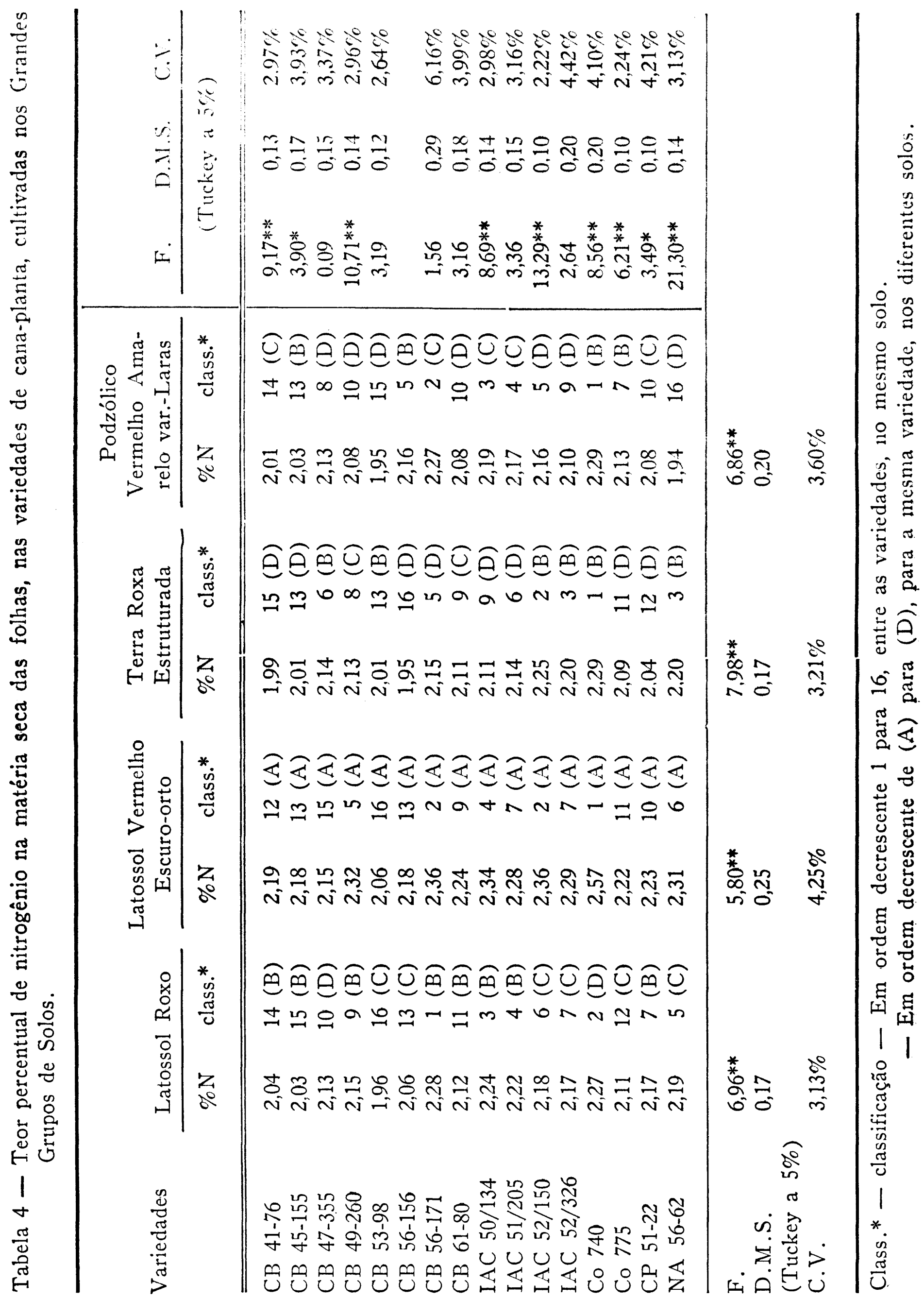




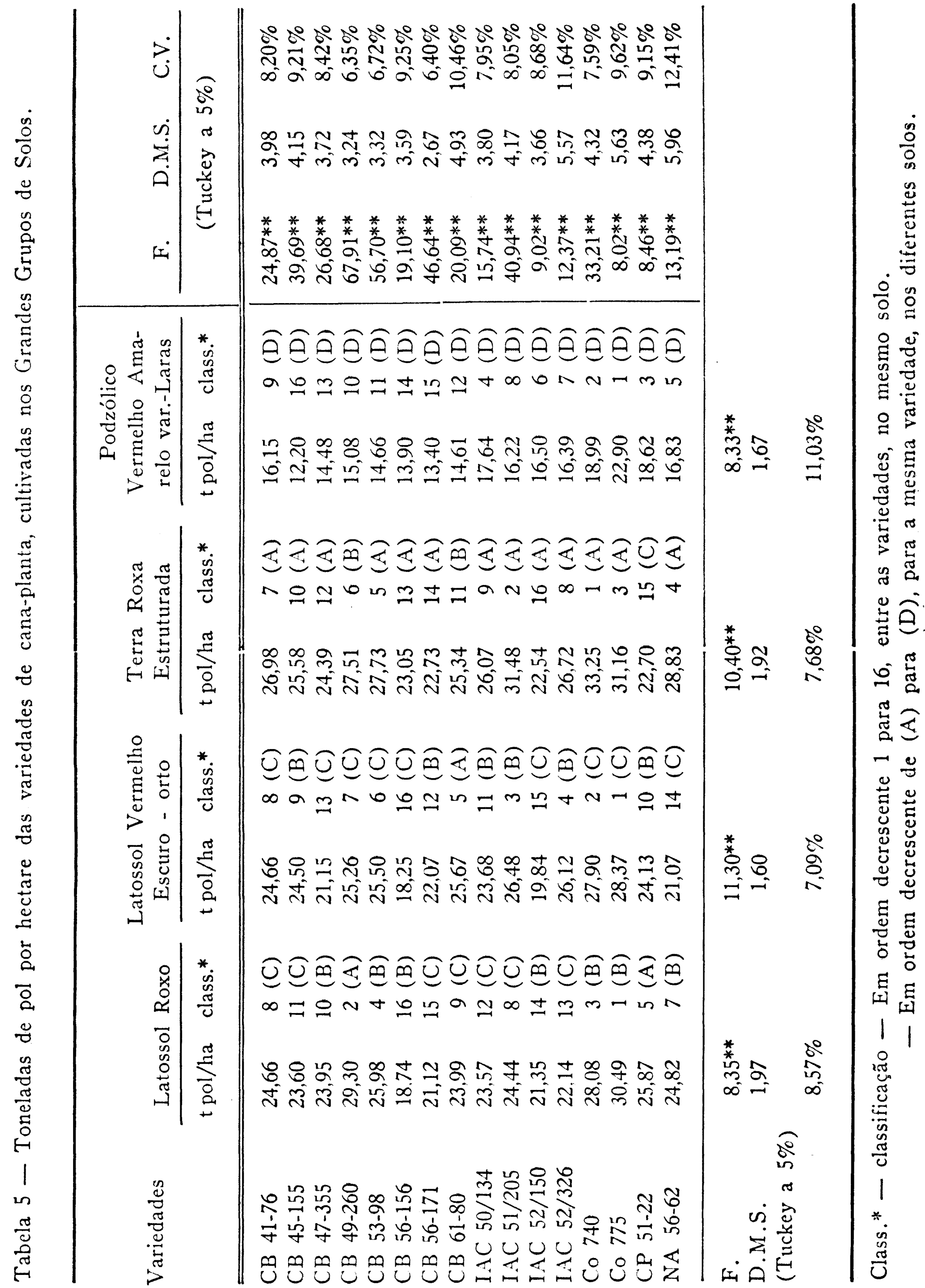




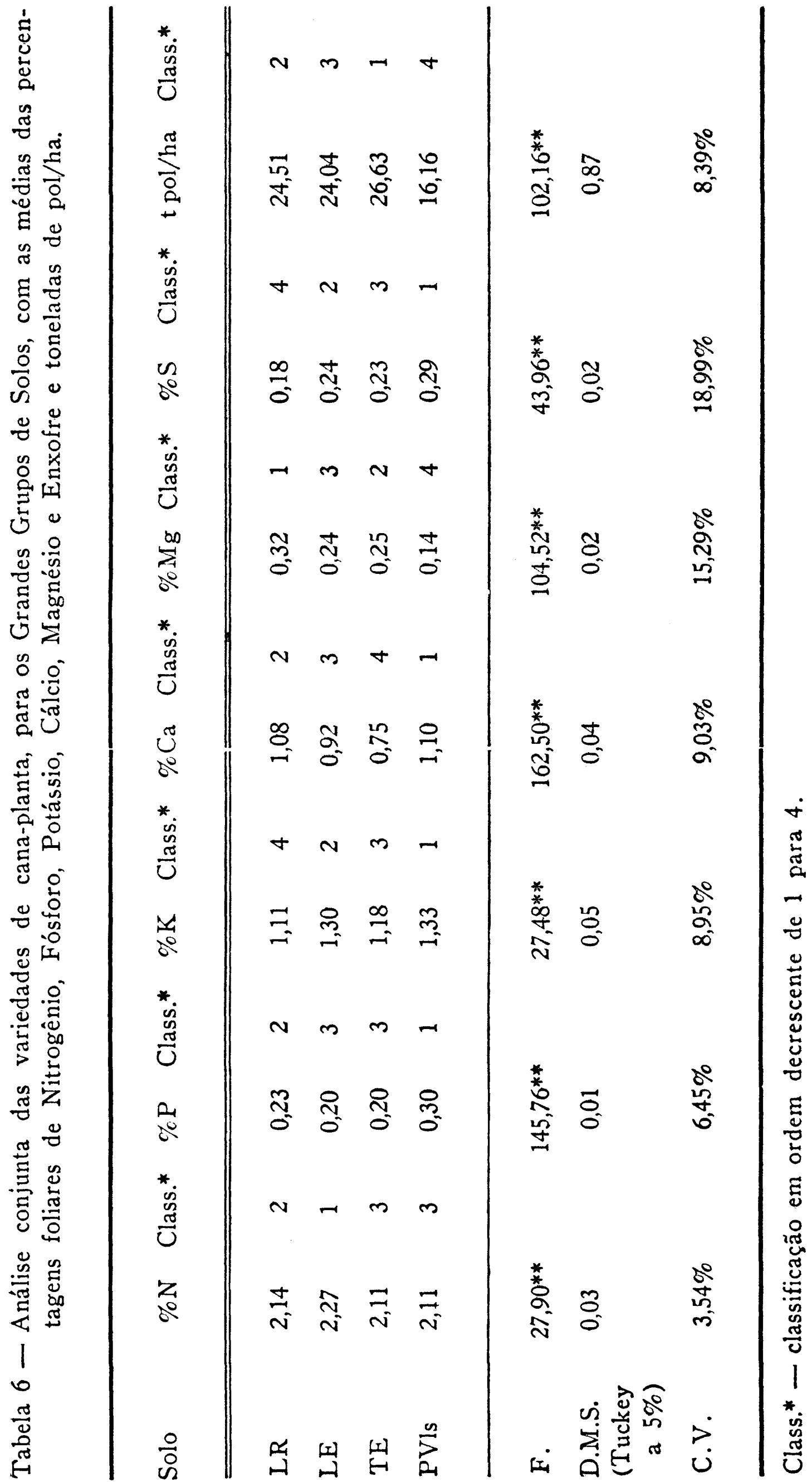


Inglesa, HALAIS (1962) em Mauritius, VITLOS \& LAWRIE (1963), em Trindade e ESPINOZA (1973) no México e mais elevados do que os observados por FOGLIATA \& DIP (1970) na Argentina. Considerando-se os dados propostos por GOLDEN \& RICAUD, citados por HUMBERT (1974), o estado nutricional das variedades do presente trabalho poderia ser considerado como muito alto, em relação ao nitrogênio.

\section{2 - Fósforo}

A tabela 7 assinala as percentagens foliares de fósforo, para as 16 variedades nos 4 Grandes Grupos, com as respectivas avaliações estatísticas (entre diferentes variedades no mesmo solo e para a mesma variedade nos diferentes solos). Pelo exame da referida tabela, observa-se que houve influência varietal e do solo nos teores de fósforo das folhas.

Foram observados os seguintes parâmetros de variação:

Solo Variação nos teores

$\begin{array}{ll}\text { LR } & 0,26 \%-0,20 \% \\ \text { LE } & 0,25 \%-0,15 \% \\ \text { TE } & 0,22 \%-0,18 \% \\ \text { PVls } & 0,35 \%-0,26 \%\end{array}$

Nota-se que as maiores variações foram as acusadas pelas variedades do solo LE. Porém, para os 4 solos, as variações percentuais, encontradas no presente trabalho, são inferiores às mostradas por KIRTIKAR \& BAJPAI (1971), na Índia e superiores às de GALLO et alii (1968) no Brasil, GOSNEL \& LONG (1971) na Rodesia, HALAIS (1959 e 1964) em Mauritius e SAMUELS et alii (1960), em Porto Rico, quando estes utilizaram diferentes variedades de cana-de-açúcar.

A CB 53-98, mesmo não tendo apresentado, para os diferentes solos (tabela 7, elevados valores foliares de fósforo, mostrou boas produções de pol/ha (tabela 5). Já as CB 56-156 e CB 56-171, apesar de indicarem elevados valores de fósforo nas folhas, foram as que menos pol/ha produziram. Por outro lado, as variedades Co 740 e Co 775 revelaram altos valores de fósforo nas folhas e elevadas produções de pol/ha. Os 


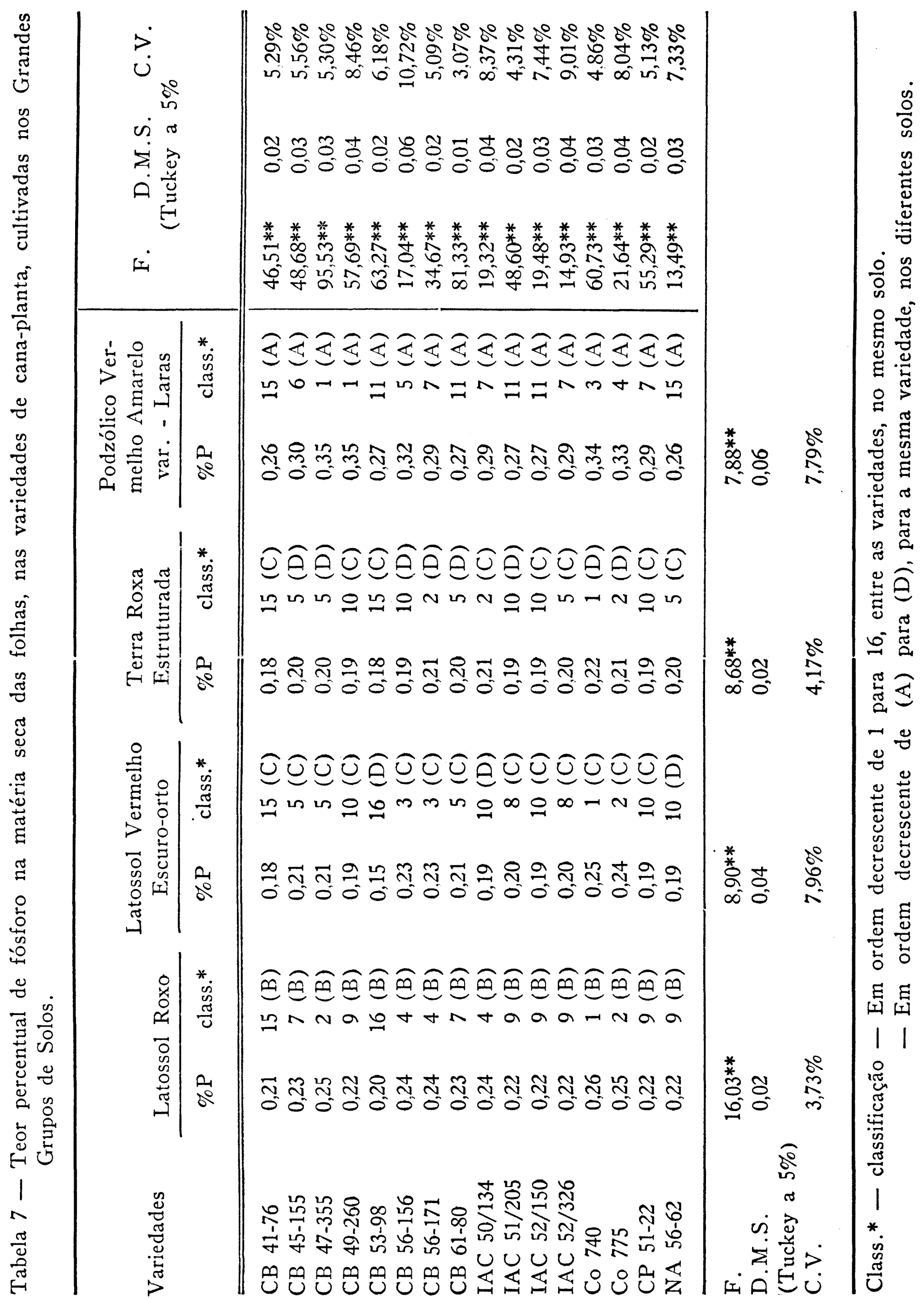


índices foliares de fósforo das variedades Co 740 e Co 775 do presente trabalho, sempre foram superiores àqueles encontrados por COURY et alii (1957), quando utilizaram a Co 419.

$\mathrm{Na}$ análise conjunta para as 16 variedades, levando-se em conta os 4 Grandes Grupos de Solos (tabela 6), o PVls indicou os mais elevados teores de fósforo nas folhas, vindo a seguir o LR e posteriormente a TE e LE. Observou-se que a alta concentração de fósforo acusada pela análise do solo, no PVls, (tabela 1) correspondeu a altos teores foliares de fósforo, em todas as variedades no referido solo.

As variações nos teores foliares de fósforo, no presente trabalho, tendo em vista o Grande Grupo de Solo, foram superiores aos mostrados por VITLOS \& LAWRIE (1963) em Trinidade e SILVA (1972) no Brasil.

$E$ interessante notar que todas as variedades, quando analisadas isoladamente e tendo em vista o Grande de Solo (tabela 7), mostraram diferenças estatísticas significativas nos teores foliares de fósforo, principalmente devido aos altos valores desse elemento apresentados pelas mesmas no Solo PVls.

Em relação ao levantamento do estado nutricional, todas as variedades (exceção a CB 53-98 no LE), apresentaram valores foliares de fósforo, igual ou superiores a $0,18 \%$, o que estaria de acordo ou muito próximos aos encontrados por MALAVOLTA et alii ,1956b, 1963 e 1974) no Brasil, INNES (1959) na Jamaica, EVANS (1961) na Guiana, HALAIS (1962) em Mauritius e DU TOIT (1959) na África do Sul. Porém, os mesmos são mais elevados que as concentrações propostas como adequadas por FOGLIATA \& DIP (1970) na Argentina e ESPINOZA (1973) no México.

De acôrdo com a classificação proposta por GOLDEN e RICAUD, citados por HUMBERT (1974), em relação ao fósforo, e considerando os valores apresentados na tabela 7 , as variedades cultivadas no PVls estariam em estado nutricional muito alto, as do LR em alto, e as da TE e LE, em médio.

\section{3 - Potássio}

As percentagens de potássio nas folhas das 16 variedades, cultivadas nos 4 Grandes Grupos de Solos, com as respectivas avaliações estatísticas (entre diferentes variedades no mesmo solo e entre mesma variedade nos diferentes solos) são expostas na tabela 8, onde verifica-se a influência varietal e do solo.

Os seguintes parâmetros de variação foram observados: 


\begin{tabular}{|c|c|}
\hline Solo & Variação nos teores foliares de enxofre \\
\hline LR & $0,28 \%-0,13 \%$ \\
\hline LE & $0,32 \%-0,18 \%$ \\
\hline $\mathrm{TE}$ & $0,31 \%-0,18 \%$ \\
\hline PVls & $0,50 \%-0,22 \%$ \\
\hline
\end{tabular}

Observa-se que o potássio apresentou grandes variações na composição foliar, em função das variedades estudadas, sendo que a gama dessas variações nos solos LR, LE e TE, ultrapassa a $100 \%$. O solo que ofereceu o maior contraste foi o LR. Tais extremos, quando colocados em função de variações percentuais, são menores do que os encontrados por KIRTIKAR \& BAJPAI (1971), na India e maiores do que os mostrados por SAMUELS et alii (1960) em Porto Rico, HALAIS $(1959$ e 1964) em Mauritius, GALLO et alii (1968) no Brasil e GOSNEL \& LONG (1971 na Rodésia.

Para a maioria das variedades, o potássio foi um elemento que apresentou bastante similaridade quanto a classificação em relação à su concentração foliar, quando comparado o comportamento das variedades nos Grandes Grupos de Solos (tabela 8) .

As variedades CB 53-98 e Co 740, mesmo com menores teores de potássio nas folhas, mostraram altas produtividades de pol, ao passo que a CB 49-260 acusou elevados valores foliares de potássio, acompanhados de altas produções de pol/ha. Já a CB 56-156, apesar de indicar folhas com maiores teores de potássio, mostrou baixas produtividades de pol.

Verificou-se também, que na análise conjunta para as 16 variedades, e considerando-se os 4 Grandes Grupos de Solos (tabela 6), que o PVls apresentou plantas com elevados teores foliares de potássio, sendo seguido pelo LE, LR e TE, respectivamente. E interessante também notar que os teores médios de potássio nas folhas das 16 variedades, para os 4 solos estudados (tabela 6), parece não terem conservado relação com o teor de potássio revelado pela análise do solo (tabela 1), e sim com o cálcio disponível no solo, mantendo com esta proporção inversa, isto é, quanto maior for o ter de cálcio revelado pela análise do solo, menor índice de potássio na folha. Por outro lado, a baixa concentração de magnésio no solo apresentada pelo PVls, parece ter contribuído para um maior teor de potássio nas folhas, o que estaria de acordo com EVANS (1961). 


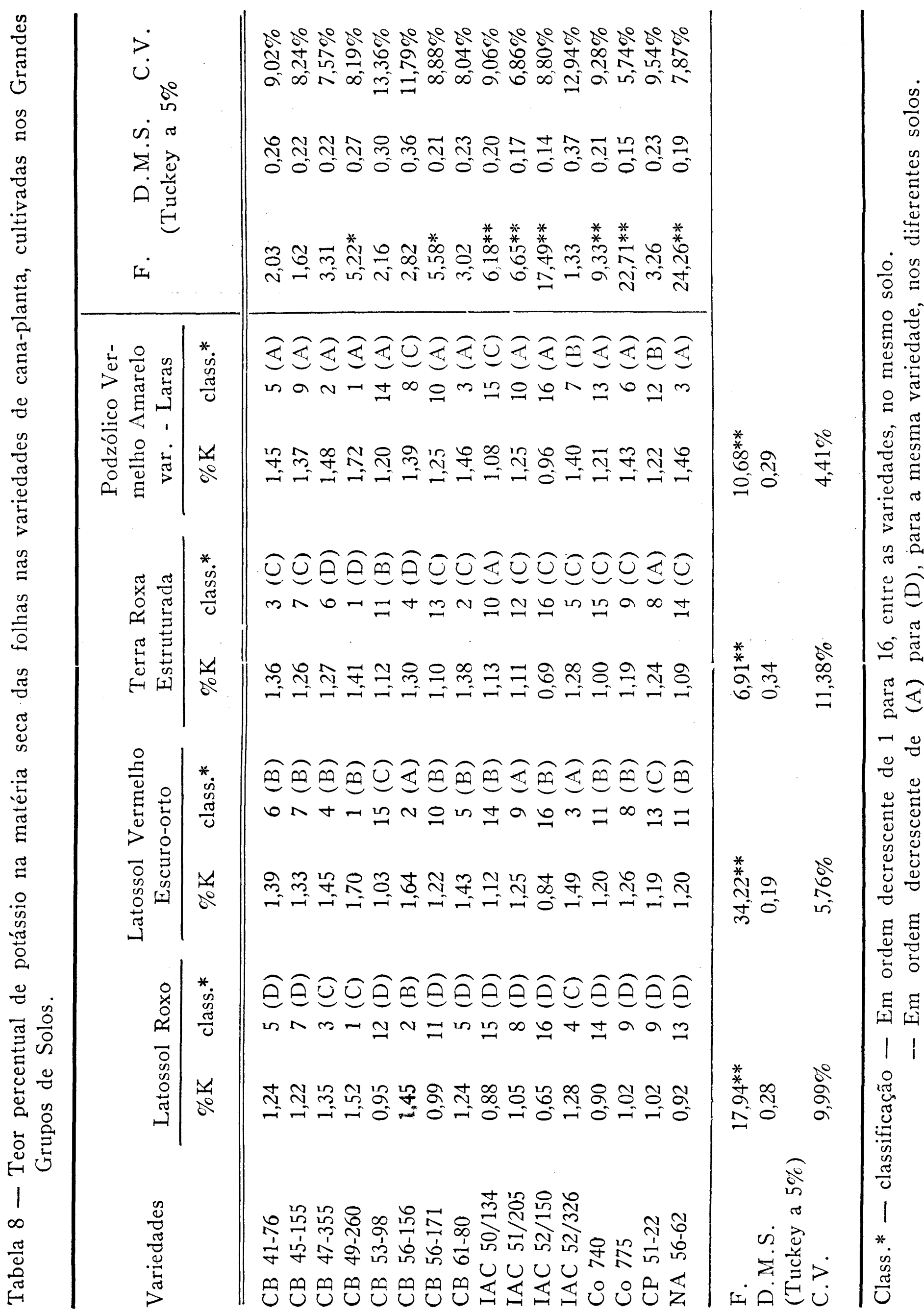


No presente trabalho, a influência do Grande Grupo de Solo na concentração de potássio nas folhas (tabela 6) foi inferior às encontradas por VITLOS \& LAWRIE (1963) em Trinidad e SILVA (1972) no Brasil.

As variedades CB 41-155, CB 47-355, CB 53-98, CB 56-156, CB 61-80, IAC 52/326 e CP 51-22, não mostraram diferenças estatísticas significativas nos teores de potássio das folhas, quando cultivadas nos 4 Grandes Grupos de Solos (tabela 8); porém, semelhante estudos realizado para tais variedades e considerando-se as produções de pol/ha. as mesmas indicaram diferenças estatísticas significativas (tabela 5) principalmente devido às baixas produtividades de pol, no solo PVls.

Quanto ao levantamento do estado nutricional, algumas variedades revelaram valores inferiores aos mínimos propostos por INNES (1959) na Jamaica, DU TOIT (1959) na África do Sul, EVANS (1961) e POIDEVIN (1964) na Guiana Inglesa, HALAIS (1962) em Mauritius, onde o teor mínimo de potássio nas folhas, para todos os países citados, estaria em torno de 1,25\%; e também abaixo dos índices mínimos sugeridos por VITLOS \& LAWRIE (1963) em Trinidade, FOGLIATA \& DIP (1970) na Argentina e STEWARD (1969) na África do Sul e MALAVOLTA et alii (1959b e 1974) no Brasil onde tal nível estaria ao redor de $1,10 \%$ de potássio. Já, considerando os valores mínimos propostos por SAMUELS et alii (1951) para o Havaí e Porto Rico, MALAVOLTA et alii (1962) no Brasil, ESPINOZA (1973) no México, somente a CB 49-260 alcançaria tais níveis no LE e PVls. Em relação ao estudo nutricional sugerido por GOLDEN \& RICAUD, citados por HUMBERT (1974), verificamos que a IAC 52/150, estaria em um estado muito baixo, nos 4 solos, o mesmo acontecendo com a CB 53-98, CB 56-171, IAC 50/134, Co 740 e NA 56-62 em solo LE; as demais variedades estariam em estado baixo ou médio.

As percentagens foliares de potássio, encontradas no atual trabalho, para a CB 41-76, foram inferiores às obtidas por MALAVOLTA et alii (1963) para a mesma variedade.

\section{4 - Cálcio}

A tabela 9 , indica as percentagens de cálcio nas folhas das 16 variedades, para os 4 Grandes Grupos de Solos e respectivas avaliações estatísticas (entre diferentes variedades no mesmo solo e entre a mesma nos diferentes solos), notando-se a influência varietal e do solo, na concentração do citado elemento nas folhas.

Observou-se os seguintes parâmetros de variação: 


$\begin{array}{ll}\text { LR } & 0,45 \%-0,22 \% \\ \text { LE } & 0,36 \%-0,16 \% \\ \text { TE } & 0,38 \%-0,16 \% \\ \text { PVls } & 0,23 \%-0,08 \%\end{array}$

As oscilações mais elevadas nos teores de cálcio das folhas, foram encontradas nas variedades cultivadas no solo TE. As variações, nos 4 solos, foram inferiores às encontradas por KIRTIKAR \& BAJPAI (19713 na India e GOSNELL \& LONG (1971) na Rodésia, porém superiores ao mostrado por GALLO et alii (1968) no Brasil.

As classificações das variedades incluídas na Tabela 9 não mostraram muita similaridade para os 4 Grandes Grupos de Solo (exceção às variedades IAC 50/134, IAC 51/205 e IAC/150) .

A comparação da tabela 9 (teores foliares de cálcio) com a tabela 5 (produção de pol/ha) indica que as variedades que ocusaram as maiores percentagens de cálcio nas folhas, não foram as mais produtivas em relação a pol/ha.

Apenas a variedade IAC 52/150 não ofereceu diferenças estatísticas significativas nos teores de cálcio das folhas, quando cultivadas nos 4 Grandes Grupos de Solos. Porém, em relação às produções de pol/ha, as diferenças foram significativas.

O exame da tabela 6 mostra que na análise conjunta, os maiores teores de cálcio foram encontrados nas folhas das variação percentual desses valores são inferiores à encontrada por SILVA (1972) no Brasil. E interessante notar que a TE (apesar da análise do solo ter revelado 13,40 me de $\mathrm{Ca}+2 / 100 \mathrm{ml}$ solo) foi a que mostrou os menores teores foliares de cálcio, sendo que as maiores concentrações foliares do citado elemento, foram observadas nas canas cultivadas em PVls $(2,07$ me de $\mathrm{Ca}^{+}$2/100 $\mathrm{ml}$ de solo) .

A IAC 52/150, em todos os solos estudados, revelou as mais elevadas concentrações foliares de cálcio, em oposição aos menores valores que a mesma apresentou em relação potássio.

MALAVOLTA et alii (1959 b), no Brasil, encontraram para o Co 419 , valores de cálcio que variavam entre $1,21 \%$ a $0,68 \%$ dados estes que se aproximam bastante dos obtidos neste trabalho. 


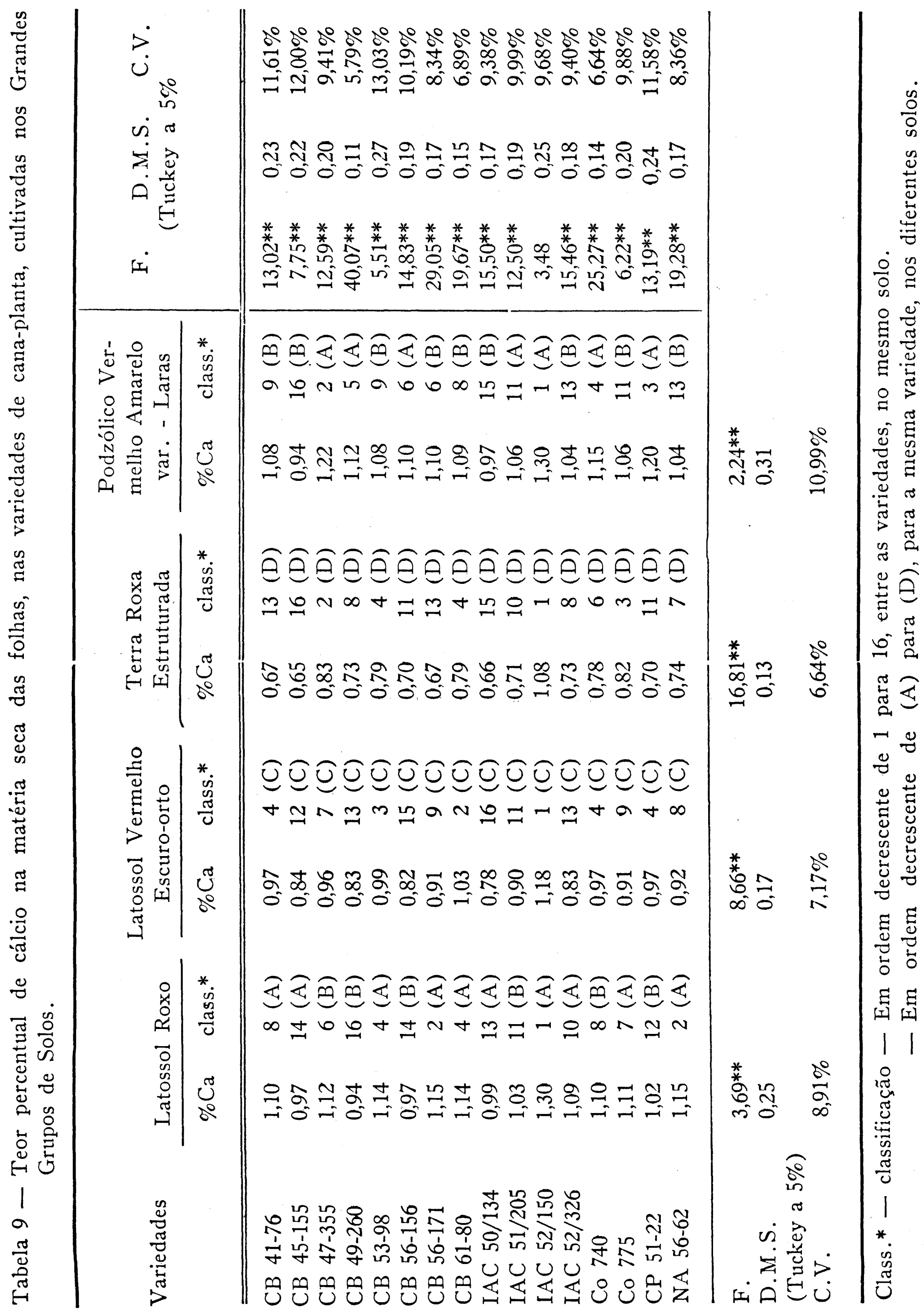


Quanto ao levantamento do estado nutricional, verificou-se que os teores foliares de cálcio apresentados pelas variedades em estudo, são bastante superiores aos considerados como normais por EVANS (1961) na Guiana Inglesa, MALAVOLTA \& COURY (1963) no Brasil, FOGLIATA \& DIP (1970) na Argentina; porém, os mesmos parecem enquadrar-se mais aos dados propostos por MALAVOLTA et alii (1974) no Brasil, onde os teores foliares normais para o cálcio seriam de $0,75 \%$ a $1,00 \%$.

\section{5 - Magnésio}

Os teores foliares de magnésio, para as 16 variedades em estudo nos 4 Grandes Grupos de Solos, com as respectivas avaliações estatísticas (entre diferentes variedades no mesmo solo e entre mesma variedade nos diferentes solos), são mostrados na tabela 10 , onde verifica-se a influência varietal e do solo.

Os seguintes parâmetros de variação foram observados:

$\begin{array}{ll}\text { LR } & 1,30 \%-0,94 \% \\ \text { LE } & 1,18 \%-0,78 \% \\ \text { TE } & 1,08 \%-0,65 \% \\ \text { PVls } & 1,30 \%-0,94 \%\end{array}$

O magnésio, dos 6 nutrientes estudados, foi o que apresentou, entre as variedades para os 4 solos, as maiores variações nos teores foliares, sendo as mesma sempre superiores a $100 \%$. Porém, tais variações foram inferiores às obtidas por KIRTIKAR \& BAJPAI (1971) na Índia e superiores às de GOSNELL \& LONG (1971) na Rodésia.

De um modo geral, as variedades mostraram classificação semelhante, nos 4 Grandes Grupos de Solos, quanto as concentrações de magnésio nas folhas.

As variedades Co 740 e Co 775 apresentaram altos teores foliares de magnésio, acompanhados de elevadas produtividades de pol, enquanto que as CB 56.156 e CB 56.171 e IAC 52/150 mostraram baixos valores de magnésio nas folhas e pol/ha (tabelas 10 e 5). 


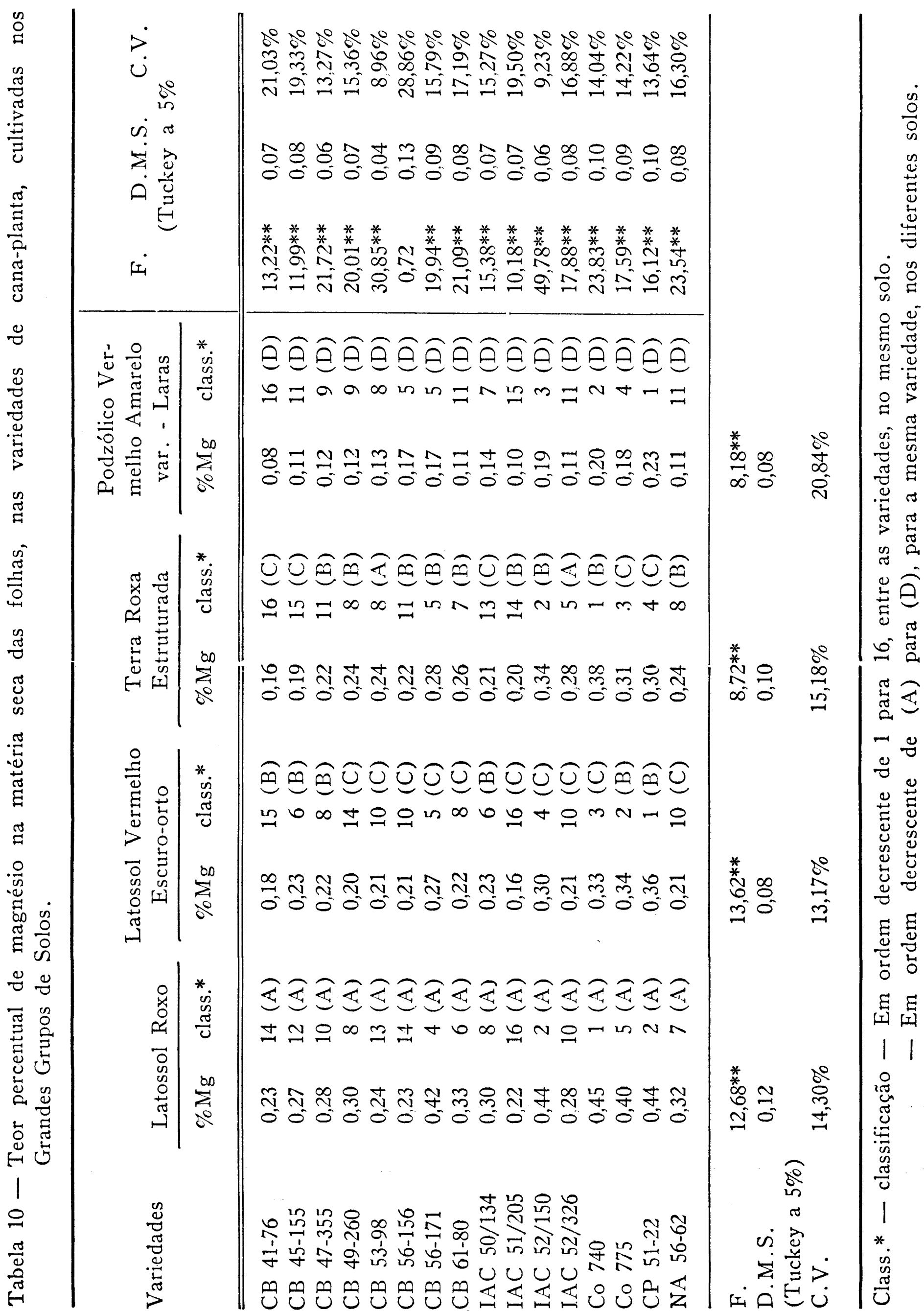


Apenas a CB 56-156, indicou para os 4 Grandes Grupos de Solos, teores de magnésio nas folhas que não diferiram entre si, do ponto de vista estatístico, porém em relação à produção de pol/ha, apresentou significância (tabelas 10 e 5).

Pelo exame da tabela 6, verifica-se a influência dos Grandes Grupos de Solos, na composição foliar de magnésio, as quais foram superiores às encontradas por SILVA (1972) no Brasil .

O LR foi o solo que mostrou os teores mais altos do citado elemento, sendo seguido pelo LE, TE e PVls, respectivamente. O PVls (0,48 me de $\mathrm{Mg}^{+} 2 / 100 \mathrm{ml}$ de solo) exibiu os índices mais baixos de magnésio nas folhas.

Em relação ao levantamento do estado nutricional, notou-se que os valores obtidos no atual trabalho, com exceção da maioria das variedades cultivadas em PVls, estariam dentro dos níveis considerados normais por EVANS (1961) na Guiana Inglesa. Todavia os teores considerados normais por MALAVOLTA \& COURY (1963) no Brasil e FEILLAFE, citado por HUMBERT (1974), em Mauritius, são mais baixos (0,1\% de $\mathrm{Mg}$ ) e englobariam todas as variedades (menos a CB 41-76 em PVls). Já HUMBERT (1974) considera que teores foliares entre 0,08\% a $0,35 \%$ de magnésio, estariam relacionados com o bom desenvolvimento da planta.

MALAVOLTA et alii (1956 b) no Brasil, encontraram para Co 419 , valores de magnésio que oscilaram entre $0,20 \%$ a $0,55 \%$ os quais são de um modo geral, superiores aos obtidos no presente trabalho, enquanto que os indicados por FOGLIATA e DIP (1970) na Argentina, foram inferiores.

\section{6 - Enxofre}

A tabela 11 revela os teores foliares de enxofre para as 16 variedades cultivadas nos 4 Grandes Grupos de Solos, com as respectivas avaliações estatísticas (entre diferentes variedades no mesmo solo e entre mesma variedade nos diferentes solos), onde nota-se a influência varietal e do solo.

Observam-se os seguintes parâmetros de variação:

\begin{tabular}{cc}
\hline Solo & Variação nos teores foliares de potássio \\
\hline LR & $1,52 \%-0,65 \%$ \\
LE & $1,70 \%-0,84 \%$ \\
TE & $1,41 \%-0,69 \%$ \\
PVls & $1,72 \%-0,96 \%$ \\
\hline
\end{tabular}


Nota-se que as maiores variações foram apresentadas pelas variedades do solo PVls. Porém, as variações para os 4 solos, encontradas no presente trabalho, são superiores às mostradas por GALLO et alii (1968) no Brasil.

De um modo geral, as variedades mostraram classificação semelhante, quanto aos teores de enxofre nas folhas, para os 4 solos em estudo (tabela 11).

A Co 740 revelou altos teores de enxofre nas folhas e altas produções de pol/ha. Já a IAC 52/150, apesar dos elevados teores foliares de enxofre, foi a variedade que indicou as mais baixas produtividades de pol.

Em relação aos 4 GrandesGrupos de Solos, no que diz respeito a análise conjunta das variedades ,tabela 6), o PVls (com 1,36\% de carbono no solo) foi o que mostrou folhas com os teores mais elevados de enxofre, seguindo-se LE, TE e LR (send que todos os três possuiam teores de carbono no solo, superiores ao PVls - Tabela 1). Portanto teores mais elevados de carbono no solo, parece não influirem em maiores concentrações de enxofre nas folhas.

As variedades CB 47-355, CB 53-98, CB 56-171, CB 61-80 e IAC $51 / 205$, não mostraram diferença estatisticamente significativas em relação às concentrações foliares de enxofre, quando cultivadas nos 4 diferentes solos (tabela 11). Porém, as mesmas variedades apresentaram diferenças significantes quando analisadas sob o ponto de vista de produtividade de pol.

As variações nos teores foliares de enxofre do presente trabalho, tendo em vista a variação de solo, foram superiores àquelas encontradas por SILVA (1972), no Brasil.

Quanto ao levantamento do estado nutricional, e considerando o valor de $0,17 \%$ de enxofre na folha, considerado como normal por MALAVOLTA \& COURY (1963) no Brasil, a quase totalidade das variedades do presente trabalho apresentou valores superiores ao mesmo. Por outro lado, HUMBERT (1974) considera que teores foliares de enxofre em folhas de cana-de-açúcar podem variar de $0,03 \%$ a $1,00 \%$.

\section{7 - Observações Gerais}

Dos nutrientes estudados, o nitrogênio foi o elemento que para os 4 Grandes Grupos de Solos e em função das 16 variedades, apresentou, entre elas, os menores parâmetros de variação na composição foliar, 


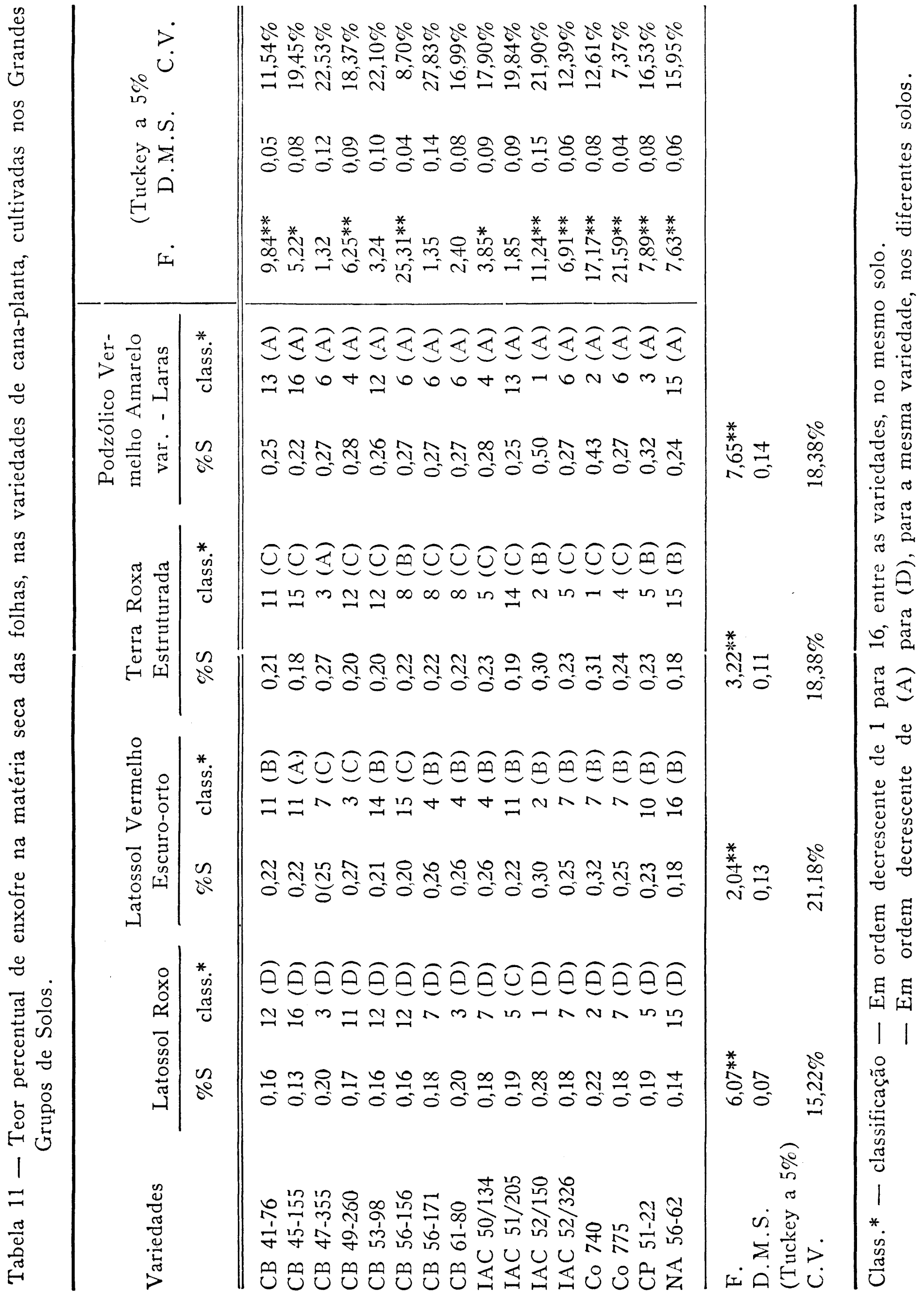


enquanto que o magnésio mostrou os maiores. Teores mais elevados de fósforo, revelados pela análise do solo, refletiram em maiores valores do citado elemento, enquanto que para o cálcio notou-se o inverso. Para os demais nutrientes não se observou relação entre o resultado da análise do solo e o teor do elemento na folha.

O solo PVls, apesar de ter produzido os mais baixos valores de $t$ de $\mathrm{pol} / \mathrm{ha}$, acusou, na análise conjunta das variedades (tabela 6), os mais elevados teores foliares de fósforo, potássio, cálcio e enxofre.

Em relação ao levantamento do estado nutricional pela diagnose foliar, exceção a algumas variedades no que diz respeito ao potássio nos 4 solos e para o magnésio no solo Podzólico Vermelho Amarelo variação Laras, as mesmas se apresentaram dentro dos padrões considerados normais nas diversas regiões canavieiras do globo.

Considerando-se o resultado do presente trabalho, sugere-se maior elasticidades nos padrões da diagnose foliar em cana-de-açúcar, como norma indicativa de levantamento do estado nutricional da cultura, e que os mesmos sejam interpretados cuidadosamente.

Em uma programação genética para obtenção de novas variedades de cana-de-açúcar, seria recomendável que após o final da seleção, enquanto que as novas variedades estivessem sendo multiplicadas comercialmente, fosse elas colocadas em ensaios de adubação, onde se verificaria a resposta a adição de diferentes doses de nutrientes em diferentes solos e ao mesmo tempo se determinaria os padrões para a diagnose foliar.

Em relação às produtividades de pol *, devemos mencionar que, em termos de talhões comerciais, a média geral para a cana-planta de 18 meses de ciclo é de $15 \mathrm{t}$ de pol/ha para o Estado de São Paulo e $17 \mathrm{t}$ de pol/ha para oEstadodo Paraná.

A tabela 12 , no sentido de melhor visualização dos valores podrões da diagnose foliar na cana-de-açúcar, mostra a classificação arbitrária das variedades quanto aos teores foliares de macronutrientes e produtividades (t pol/ha), onde considerou-se valores altos, médios e baixos, seguindo-se o seguinte critério (arbitrário):

* Informação do Departamento Técnico da Superintendência Geral do Planalsucar (Programa Nacional do Melhoramento da Cana-de-Açúcar) - Rua Boa Morte, 1367 - Piracicaba São Paulo. 


\begin{tabular}{lccc}
\hline \multirow{2}{*}{ Elemento } & \multicolumn{3}{c}{ Teor Foliar (\%) } \\
\cline { 2 - 4 } & Alto & Médio & Baixo \\
\hline \hline $\mathrm{N}$ & $>2,20$ & $2,20-2,00$ & $<2,00$ \\
$\mathrm{P}$ & $>0,24$ & $0,24-0,20$ & $<0,20$ \\
$\mathrm{~K}$ & $>1,30$ & $1,30-1,10$ & $<1,10$ \\
$\mathrm{Ca}$ & $>1,10$ & $1,10-0,90$ & $<0,90$ \\
$\mathrm{Mg}$ & $>0,30$ & $0,30-0,20$ & $<0,20$ \\
$\mathrm{~S}$ & $>0,30$ & $0,30-0,20$ & \\
\hline
\end{tabular}
valores:

Para a produtividade de pol (t pol/ha) observaram-se os seguintes

$>24 \quad \mathrm{t} \mathrm{pol} / \mathrm{ha}$ - produtividade alta

24-18 t pol/ha - produtividade média

$<24$ t pol/ha - produtividade baixa

\section{6 - CONCLUSǑES}

O presente trabalho permitiu as seguintes conclusões:

a) Independentemente do Grande Grupo de Solo, há influência varietal, nos teores foliares de macronutrientes;

b) Altos valores de nutrientes nas folhas, nem sempre refletem elevadas produções de $\mathrm{pol} / \mathrm{ha}$;

c) O Grande Grupo de Solo influi significativamente na concentração de macronutrientes das folhas das variedades;

d) Em vista da influência varietal e do solo na composição de macronutrientes das folhas, verifica-se a incoveniência de uma generalização do nível crítico, na aplicação da diagnose foliar em cana-de-açúcar;

e) Há dificuldade na escolha de uma variedade, que represente as demais, para o estabelecimento dos podrões da diagnose foliar. 


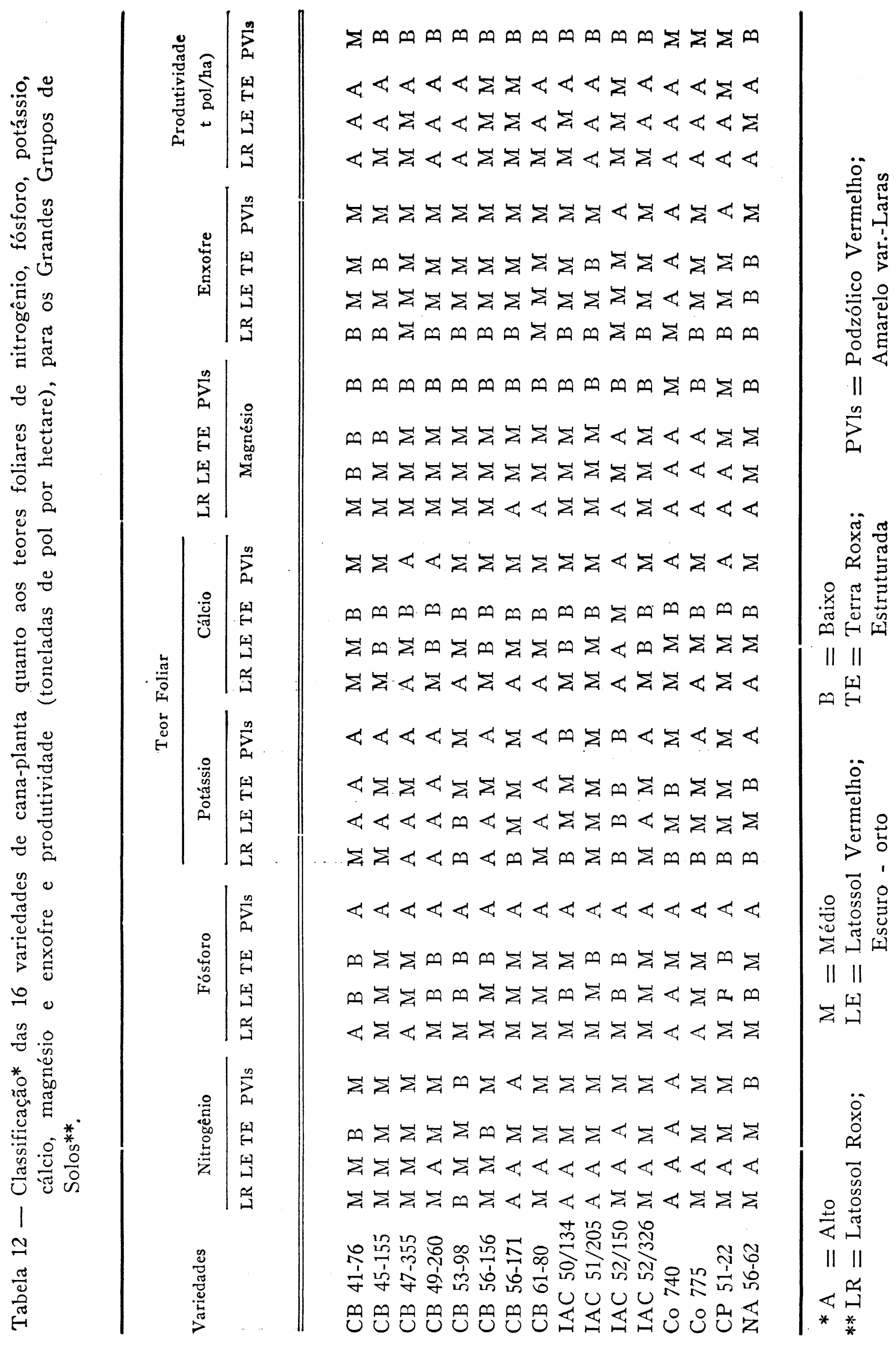




\section{SUMMARY}

"VARIETAL AND SOIL INFLUENCE ON NUTRITIONAL STATUS OF SUGARCANE (SACCHARUM SPP) AS DETERMINED BY FOLIAR ANALYSIS"

Trials were established on four soil types (Latosolic B Terra Roxa - LR; Ortho Dark Red Latosol - LE and Red Yellow Podzolic Laras variation - PVls in the state of São Paulo and Textural B Terra Roxa - TE in Paraná to study varietal and soil effects on macronutrient composition of sugarcane leaves and to do a nutritional survey of varieties by foliar analysis.

A randomized block designwas used with four replications of 16 varieties (CB 41-76; CB 45-155; CB 47-355; CB 49-260; CB 56-171; CB 61-80; IAC 50/134; IAC 51/205; IAC 52/150; IAC 52/326; Co 740; Co 775; CP 51-22 and NA 56-62).

Varieties were planted under the same conditions of climate, fertilization, tillage and age, sanitation and source.

A central $20 \mathrm{~cm}$ portion of each +3 leaf was taken (except for midrib for determining amounts of $\mathrm{N}, \mathrm{P}, \mathrm{K}, \mathrm{Ca}, \mathrm{Mg}$ and $\mathrm{S}$, expressed on a dry weight basis.

Leaf samplesof 20 leaves per plot were selected at four months of age, for analysis.

From the results obtained it was conclued that:

a) There is a varietal effect on leaf composition of major elements, independent of soil type;

b) Soil type has an influence on leaf composition of different varieties;

c) The higher nutrient levels in the leaves did not always result in the highest production in $\mathrm{t} \mathrm{pol} / \mathrm{ha}$;

d) Because of soil and varietal influence on leaf composition it is rifficult to generalize critical nutrient levels obtained from foliar diagnosis;

e) Critical levels of nutrients obtained from foliar diagnosis for une variety do not represcnted the same levels for all varieties.

\section{LITERATURA CITADA}

ALVAREZ, F.G. 1974. - Correlacion entre algunos niveles de nutrientes el la hoja de la caña de azucar. Rev. Fac. Agr. Univ. Cent. Venez., 7 (4) : 5-12.

AZZI, G.M. 1971 - A situação das variedades de cana-de-açúcar cultivadas no Estado de São Paulo. Brasil Açucareiro, 78 (3) : 26-29.

BOWEN, E.J. 1975 - Micronutrient composition of sugarcane sheaths as affected by age. Trop. Agr., Trin., 52,(2) : 131-37.

BUCHANAN, E.J. 1966 - Direct sampling and analysis of individual cane consignments.

CATANI, R.A. \& O. JACINTO. 1974 - Análise química para avaliar a fertilidade do solo. Piracicaba, ESALQ/USP, 57 p. (Boletim Técnico Científico n. ${ }^{\circ} 37$ ). 
COMISSAO DE SOLOS. 1960 - Levantamento de reconhecimento dos solos do Estado de São Paulo. Rio de Janeiro, Ministério da Agricultura, Centro Nacional de Pesquisas Agronômicas, 634 p. (Boletim n. $\left.{ }^{\circ} 12\right)$.

COURY T.; E. MALAVOLTA; F. PIMENTEL GOMES; O. VALSECHI; J.D.P. ARZOLLA; M.O.C. BRASIL SOBRINHO; H.P. HAAG; F.A.F. MELLO; R.F. NOVAES; G. RANZANI e L. NEPTUNE MENARD. 1957 - A diagnose foliar em cana-de-açúcar. I - Resultados preliminares, São Paulo, 28 p. (Apresentado ao VI Congresso Brasileiro de Ciência do Solo, Salvador - BA, 1957).

CRUZ, C.R.F. 1973 - Philsugin - The first 20 years. Sugar News, 49 (10-11) : 355-97.

DANIELS. J. 1971 - A standardised naming system for sugarcane clones. Sugarcane Pathologists Newslâetter.

DILLEWJIN, C. VAN. 1952 - Botany of sugarcane. Waltham, Chronica Botanica, 371 p.

DU TOIT, J.C. 1959 - Recent advances in nutrition of sugarcane in South Africa. In: Int. Soc. Sugar Cane Tech., 10, Hawaii. Procedings. Amsterdan, Elsevier, 1960, p. $432-41$.

ESPINOSA, A.G. 1973 - Manual de campo em caña de azucar. México, Instituto para el Mejoramiento de la Produccion de Azucar, $224 \mathrm{p}$.

ESPIRONELO, A. \& H. ALOVEIRA. 1972 - Orientação Geral para adubação da cana-de-açúcat no Estado de São Paulo. Campinas, Instituto Agronômico, 16 p. (Boletim n. ${ }^{\circ}$ 201).

EVANS, H. 1961 - Of nutritional diagnostic analyses of sugarcane in British Guiana. Sugar Journal, 23 (9) : 8-16.

EVANS, H. 1965 - Tissue diagnostic analyses and their interpretation in sugarcane. In: Congr. Int. Soc. Sugarcane Tech., 12, Puerto Rico. Proceedings. Amsterdam, Elsevier, 1967, p. $156-180$.

FAROUHAR, R.H. 1965 - The interpretation and use of tissue analysis within a fertilizer arvisory service for sugarcane in north Queensland. In: Congr. Int. Soc. Sugarcane Tech., 12, Puerto Rico. Proceedings. Amsterdam, Elsevier, 1967, p. 227-36.

FOGLIATA, F.A. \& R.A. DIP. 1970 - El diagnostico foliar y la fertilizacion de la caña de azucar. Rev. Ind. y Agricola de Tucuman, 46 (2): 45-71.

FRANCA. G.V. \& I.I.I. DEMATE. 1970 - Comparação entre as classificações antiga e moderna dos solos do Estado de São Paulo. O Solo, 62 (1) : 83-88.

FRANCA, G.V. \& J.L.I. DEMATE. 1971 - Projeto de levantamento de solos da área pertencente à fazenda Santa Elisa, Sertãozinho, São Paulo, 69 p., mimeografada.

GOMES, F.P. 1973 - Curso de estatística experimental. São Paulo, Nobel, 384 p.

GOSNELL, J.M. \& A.C. LONG. 1971 - Some factors affecting foliar analysis in sugnrcane. In: South Afr. Sucar Tech. Assoc., 45. Proccedings. Natal., Witness, 1971, p. 217-22.

HALAIS, P. 1959 - The determination of nitrogenous fertilizer requirement of sugarcane crops by foliar diagnosis. In: Congr. Int. Soc. Sugarcane Tech., 10, Hawaii. Proceedings. Amsterdam, Elsevier, 1960, p. 515-21.

HALAIS, P. 1952 - The detection of NPK deficiency trends in sugarcane crops by means of foliar diagnosis run from year on a follow-up basis. In: Congr. Int. Soc. Sugarcane Tech., 11. Mauritius, Proceedings. Amsterdam, Elsevier, 1963, p. 214-21.

HALAIS, P. 1964 - Foliar diagnosis, variety corrections. Mturitius Sugar Ind. Res. Inst. Annu. Rep., p. 45-47. 
HALAIS, P. \& P. NABASING. 1971 - Quantitative nitrogen requirements of four cane varieties from foliar diagnosis dara. Mauritius Sugar Ind. Res. Inst. Annu. Rep., p. 70-74.

HUMBERT, R.P. 1974 - El cultivo de la caña de azucar. Ed. em Español, México, Editorial Continental, 719 p.

ISSCT - INTERNATIONAL SOCIETY SUGAR CANE TECHNOLOGISTS. 1974 Panel discussion foliar diagnosis. The S. Afr. Sug. J., 58 (10) : 525-29.

INNES, R.F. 1959 - The manuring of sugarcane. Span, 2 (3) : 98-100.

KING, N.J.; R.W. MUNGOMERY e C.G. HUGHES. 1953 - Manual of cane growing. Sidney, Angus and Robertson, 349 p.

KIRTIKAR \& P.D. BAJPAI. 1971 - The uptake of nutrients by cane crop. II - Effect of chemical composition of leaves and canes of different varieties. Indian Sugar, 21 (7) : 491-98.

LANDRAU JR., P. \& G. SAMUELS. 1954 - Response of four sugarcane varieties to fertilizers during the first Isabela-cycle, 1946-51. J. Agr. Univ. P.R. 38 (2) : 73-95.

MALAVOLTA, E.; T. COURY; F. PIMENTEL GOMES; O. VALSECHI; M.O.C. BRASIL SOBRINHO; J.D.P. ARZOLLA; F.A.F. MELLO; H.P. HAAG; L.N. MENARD; G. RANZANI e R.F. NOVAES. 1959a - A diagnose foliar na cana-de-açúcar. II - Ensaio fatorial $\mathrm{PK} 4 \times 4$. São Paulo, 11 p. (Apresentado ao VII Congresso Brasileiro de Ciência do Solo, Piracicaba, 1959).

MALAVOLTA, E. ; T. COURY; F. PIMENTEL GOMES; J.D.P. ARZOLLA; M.O.C. BRASIL SOBRINHO; H.P. HAAG; F.A.F. MELLO; R.F. NOVAES; S. ARZOLLA e L. NEPTUNE. 1959b - A diagnose foliar na cana-de-açúcar. III Ensaio fatorial NPK $3 \times 3 \times 3$. São Paulo, 21 p. (Apresentado ao VII Congresso Brasileiro de Ciência do Solo, Piracicaba, 1959).

MALAVOLTA, E.; H.P. HAAG; F.A.F. MELLO e M.O.C. BRASIL SOBRINHO. 1962 - On the mineral nutrition of some tropical crops. Berne, International Potash Institute, $155 \mathrm{p}$.

MALAVOLTA, E.; F. PIMENTEL GOMES; T. COURY; C.P. ABREU; O. VALSECHI; H.P. HAAG; M.O.C. BRASIL SOBRINHO; F.A.F. MELLO; J.D.P. ARZOLLA; S. ARZOLLA; G. RANZANI; E.J. KIEHL; O.J. CROCOMO; L.N. MENARD; R.F. NOVAES; O. FREIRE e E.R. OLIVEIRA. 1963 - A diagnose foliar na cana-de-açúcar. IV - Resultados de 40 ensaios fatoriais NPK $3 \times 3 \times 3$, primeiro corte de São Paulo. Piracicaba, ESALQ, USP, 47 p.

MALAVOLTA, E. \& T. COURY. 1963 - Nutrição mineral de culturas de interesse econômico. Rev. São Paulo Agrícola, 5 (56) : 21-49.

MALAVOLTA, E.; H.P. HAAG; F.A.F. MELLO e M.O.C. BRASIL SOBRINHO. 1974 - Nutrição e adubação das plantas cultivadas. São Paulo, Pioneira, 727 p.

McLEAN, F.C. 1973 - A method of assorting foliar data to determine optimal levels of $\mathrm{N}$, $\mathrm{P}$ and $\mathrm{K}$ for different varieties of sugarcane. $9 \mathrm{p}$. (presented to the Meeting $\mathrm{W}$. Indian Sugar Tech.).

MEADE, G.P. 1967 - Manual del azucar de caña. Trad. Mário G. Menoral. Barcelona, Montaner y Simon, $940 \mathrm{p}$.

PAYNE, J.P. 1968 - Sugar cane factory analytical control. Amsterdam, Elsevier, 190 p.

POIDEVIN, N.L.E. 1964 - Métodos de diagnose foliar utilizados nas plantações do grupo Booker na Guiana' Inglesa. 2. ${ }^{\mathbf{a}}$ parte: Interpretação dos resultados. Fertilité, $21: 12-17$.

RUGAI, S. \& J. ORLANDO F. ${ }^{\circ} 1973$ - Cana-de-açúcar nos solos do Estado de São Paulo. Brasil Açucareiro, 82 (3): 17-23. 
SAMUELS, G; B.G. CAPO์; P. LANDRAU JR.; S. ALERS e A. RIERA. 1955 - The method of foliar diagnosis as applied to sugarcane. Bull. Agr. Exp. Sta. University of P. Rico, 47 p. (Bull. 123).

SAMUELS, G.; S. ALERS ALERS e P. LANDRAU JR. 1957 - A comparison of different leaf - sampling techniques used in the foliar diagnosis of sugarcane in different countries. J. Agr. Univ. P. Rico, 41 (1) : 1-10.

SAMUELS, G.; P. LANDRAU JR. e S. ALERS ALERS. 1960 - Influence of heigh of cane and leaf at time of sampling on leaf nutrients conten of sugarcane. J. Agr. Univ. P. R. 44 (1) : 11-15.

SAMUELS, G. 1969 - Foliar diagnosis for sugarcane. Chicago, Adams Press, 362 p.

SARRUGE, J.R. \& H.P. HAAG. 1974 - Análise química em plantas. Piracicaba, ESALQ, USP, $56 \mathrm{p}$.

SEITEC - Projetos e Desenvolvimento. 1973 - Anteprojeto da Estação Central Sul, São Paulo. Cap. 1 e 2, 42 p. Mimeografada.

SILVA, L.G. 1972 - Levantamento nutricional da cana-de-açúcar na região de Piracicaba, São Paulo. Tese apresentada à Escola Superior de Agricultura "Luiz de Queiroz" para a obtenção do título de M.S., 110 p. Mimeografada.

STEWART, J.M. 1969 - El potassio y la caña de azucar. Rev. Potassa, sec. 27 (47), $16 \mathrm{p}$.

VITLOS, A.J. \& I.D. LAWRIE. 1963 - Foliar diagnosis as a guide to the mineral nutrition of sugar-cane in Trinidad, Tropical Agriculture, 40:173-83.

WILLIANS, S.M. \& J.W. COUSTON. 1962 - Los niveles de produccion agricola y el empleo de fertilizantes. Roma, FAO, 55 p. 
